\title{
Gravity wave characteristics in the middle atmosphere during the CESAR campaign at Palma de Mallorca in 2011/2012: Impact of extratropical cyclones and cold fronts
}

\author{
R. Kramer ${ }^{\text {a,*,1 }}$, S. Wüst ${ }^{\text {a }}$, C. Schmidt ${ }^{\text {a }}$, M. Bittner ${ }^{\text {a,b }}$ \\ ${ }^{a}$ German Aerospace Center (DLR-DFD), 82234 Wessling, Germany \\ b University of Augsburg, 86135 Augsburg, Germany
}

\section{A R T I C L E I N F O}

\section{Article history:}

Received 21 August 2014

Received in revised form

3 March 2015

Accepted 4 March 2015

Available online 6 March 2015

Keywords::

Gravity waves

Energy density

Momentum flux

Extratropical cyclone

\begin{abstract}
A B S T R A C T
Based on a measuring campaign which was carried out at Mallorca $\left(39.6^{\circ} \mathrm{N}, 2.7^{\circ} \mathrm{E}\right)$ as cooperation between Agència Estatal de Meteorologia (AEMET) and Deutsches Zentrum für Luft- und Raumfahrt, engl. 'German Aerospace Center' (DLR) in 2011/2012 (September-January), 143 radiosondes (day and night) providing vertical temperature and wind profiles were released. Additionally, nocturnal mesopause temperature measurements with a temporal resolution of about 1 min were conducted by the infrared (IR) - Ground-based Infrared P-branch Spectrometer (GRIPS) during the campaign period.

Strongly enhanced gravity wave activity in the lower stratosphere is observed which can be attributed to a hurricane-like storm (so-called Medicane) and to passing by cold fronts. Statistical features of gravity wave parameters including energy densitiy and momentum fluxes are calculated. Gravity wave momentum fluxes turned out being up to five times larger during severe weather. Moreover, gravity wave horizontal propagation characteristics are derived applying hodograph and Stokes parameter analysis. Preferred directions are of southeast and northwest due to prevailing wind directions at Mallorca.
\end{abstract}

(c) 2015 Elsevier Ltd. All rights reserved.

\section{Introduction}

It is widely accepted that gravity waves (GWs) play a significant role in the dynamics of the atmosphere. The vertical transport of horizontal momentum and energy of GWs as well as wave/turbulence interactions influence the mean winds (Hines, 1960; Fritts and Alexander 2003) and especially the quasibiennal oscillation (QBO) (Lindzen and Holton, 1968). As subgrid-scale processes GWs are usually treated via parameterizations in both, numerical climate and weather-forecasting models (e.g. Stevens et al., 2013). As such models turned out to be considerably sensitive to such a parameterization, there is an ongoing need to improve them. Among others McFarlane (1987) as well as Kim and Arakawa (1995) included orographically excited GWs into this type of model. Whereas McFarlane (1987) presented the results of introducing a simple wave drag parameterization into the Canadian Climate Center general circulation model, Kim and Arakawa (1995) showed the improvements of orographic gravity wave

\footnotetext{
* Corresponding author.

E-mail address: Ricarda.kramer@dlr.de (R. Kramer).

${ }^{1}$ Formerly at University of Augsburg.
}

parameterization by using a mesoscale gravity wave model. In 2012 Pulido et al. (2012) published a technique to estimate gravity wave drag for subgrid-scale GWs from numerous sources. A review of recent studies on GW effects in stratosphere-resolving climate models was given by Alexander et al. (2010). Moreover, they published a summary of recent GW observations and analysis methods that reveal global patterns in gravity wave momentum.

Several measurement techniques are usually used to observe the spatio-temporal gravity wave characteristics to derive wave parameters for model input. These include rocketsondes (e.g. Hirota and Niki, 1985; Hamilton, 1991; Eckermann et al. 1994), lidar and radar observations (e.g. Sato, 1994; Mitchell et al., 1994; Sato et al., 1997; Li et al. 2010), aircraft (e.g. Nastrom et al., 1987; Dörnbrack et al., 2002; Doyle et al., 2002), satellites (e.g. Preusse et al., 2002; Ern et al., 2004) and radiosondes (e.g. Allen and Vincent, 1995; Vincent et al., 1997; Vincent and Alexander, 2000; Yoshiki and Sato, 2000; Wang and Geller, 2003; Gong et al., 2008). Moreover, it is possible to derive gravity wave characteristics in the upper mesosphere from airglow observations (e.g. Hines and Tarasick, 1987; Swenson et al., 2000; Bittner et al., 2002; Schmidt et al., 2013). Because of their global coverage, climatologies of gravity waves are - in principle - favored based on satellite 
measurements (e.g. Ern et al., 2004). Besides spaceborne measurements, radiosonde soundings are also appropriate for global analyses because of their wide-spread operational network.

Convective processes are known to be very effective sources for GW generation (e.g. Holton, 1983; Fritts and Alexander, 2003). Especially, cyclones contain zones with intense convection activity such as the center of the cyclone and also at the frontal regions (regions of high temperature gradients on a comparatively small horizontal range). Several studies indicate a systematic change in cyclone activity due to global change (Graham and Diaz, 2001; Ulbrich et al., 2007). This implies that also cyclone induced GW activity may be expected to change accordingly.

The focus of our work is on characterizing GW activity induced by strong cyclones and cold fronts over the Mediterranean (Mallorca-area) during autumn 2011 and winter 2011/2012 using measurements from radiosondes and airglow spectroscopy. This paper is organized as follows. Section 2 describes the data of our measuring campaign at Palma de Mallorca with Section 2.1 focussing on radiosonde data and Section 2.2 concentrating on airglow measurements. The meteorological background during the observational campaign is discussed in Section 3. Then, in Section 4 all techniques used for data processing and the methods to estimate gravity wave parameters are summarized. Section 5 presents the derived inertia-gravity wave characteristics including a discussion. In Section 6 main results are summarized and concluding remarks are given.

\section{Data}

All data were collected during the measurement campaign CESAR ("Charakterisierung des differentiellen Energiegehaltes von Vb-Zyklonen über die Quantifizierung abgestrahlter Schwere- und Infraschallwellen in der Atmosphäre", engl. "Characterisation of the differential energy content of Vb-cyclones by quantifying the radiated atmospheric gravity waves and infrasound") at Palma de Mallorca $\left(39.6^{\circ} \mathrm{N}, 2.7^{\circ} \mathrm{E}\right.$; Spain), which took place from 14 th September 2011 to 10th January 2012. Details about the campaign are given in Wüst et al. (2013).

\subsection{Radiosondes}

Radiosonde ascents were performed with high temporal resolution during seven time periods (from now on abbreviated as P1-P7) of different duration (see Table 1). During the longest period (P7) 34 radiosondes were released, whereas the shortest one (P5) contains 11 ascents. In maximum eight balloons were released each day at $02,05,08,11,14,17,20$ and 23 UTC. Routine radio soundings were conducted at 11 and 23 UTC. During P4 one sounding did not work properly (November 9 at 05 UTC, RS-P4-7). As an impression, Fig. 1 shows the time series of the temperature profiles from December 14, 2011 to December 18, 2011 (P7) at Palma de Mallorca. Each subsequent profile is shifted by an interval of $+10 \mathrm{~K}$. Profiles with well-developed GW activity can be clearly seen in the lower stratosphere. The radiosonde soundings were performed with Vaisala RS92-SGP radiosondes and TOTEX TA500 balloons. The vertical velocity of the balloons was about $5 \mathrm{~m} / \mathrm{s}$. They typically reached altitudes of $25-30 \mathrm{~km}$ (see Table 1 ) and data were sampled every $2 \mathrm{~s}$ during a balloon ascent, corresponding to a vertical resolution of about $10 \mathrm{~m}$. In general, temperature, pressure and humidity are available with an accuracy of $\sim 0.5 \mathrm{~K}, 0.6-1 \mathrm{hPa}$ and $5 \%$ relative humidity, respectively. The horizontal winds are estimated from the elevations and azimuthal angles of the radiosondes, which are measured by tracking the position of the balloons using GPS with $0.15 \mathrm{~m} / \mathrm{s}$ and $2^{\circ}$ uncertainty for velocity and directional measurement, respectively.
Investigating the final positions of all balloons showed that all radiosondes drifted eastwards either to the north or to the south. During the last period (P7) some of the balloons traveled long distances of more than $150 \mathrm{~km}$. The shortest distances were measured during the second period with at least $3 \mathrm{~km}$ at 29th October 2011, 02 UTC (RS-P2-20). Data are archived at the World Data Center for Remote Sensing of the Atmosphere (WDC-RSAT, http://wdc.dlr.de/ndmc).

\subsection{Airglow measurements}

The Ground-based Infrared P-branch Spectrometer 12 (GRIPS) was installed at the facilities of the Spanish weather institution Agència Estatal de Meteorologia (AEMET) pointing upward in the zenith direction in order to obtain nocturnal temperatures at about $87 \mathrm{~km}$ height from hydroxyl airglow. It is a medium resolution grating spectrometer with an InGaAs-photodiode array (PDA) used for the observation of the bright $\mathrm{OH}$-airglow emissions between $1.5 \mu \mathrm{m}$ and $1.6 \mu \mathrm{m}$. Thereby, a high temporal resolution of $15 \mathrm{~s}$ per spectrum is achieved. However, only one minute mean values of higher precision are used for this study (typically $2.5-8 \mathrm{~K}$ depending on recorded emission intensity). The GRIPS 12 yields the mesopause temperature based on three different vibrational-rotational intensities (OH3-1). Besides the fact that the instrument can only measure during darkness, clouds can influence the measurements. For a detailed description of the instrument and its characteristics see Schmidt et al. (2013). The GRIPS 12 is integrated into the international Network for the Detection of Mesospheric Change (NDMC), a global program with the mission to promote international cooperation among research groups investigating the mesopause region ( $80-100 \mathrm{~km})$. Data are also archived at the World Data Center for Remote Sensing of the Atmosphere (WDC-RSAT, http:// wdc.dlr.de/ndmc) with DOI doi:10.1594/WDCRSAT.79FLF9IV.

In total 119 nights with mesopause temperature measurements are available from this campaign. As an example, Fig. 2 shows the nocturnal time series of GRIPS 12 from 16th to 17th December 2011. The upper panel denotes the evolution of $\mathrm{OH}(3-1)$ rotational temperatures throughout the night (one minute mean values). The second panel marks the course of the respective emission intensity relative to its nightly mean. The lowest panel shows the uncertainties of the rotational temperatures.

\section{General meteorological conditions}

The CESAR-campaign at Palma de Mallorca was focused on periods of enhanced cyclone activity. Two time intervals were mainly used for our analysis and are therefore described in more detail below.

\section{a. Campaign phases P3-P4}

During 2nd and 4th November 2011 a pronounced cold front passed Mallorca from northwest, going along with the development of a weak cyclone core over the Spanish mainland. As the cyclone intensified, it moved towards Mallorca with its center staying more or less stationary over Mallorca for several days (4th-6th November). On the 5th November 2011 the corresponding cold front passed Mallorca. Afterwards, the cyclone moved east- and northwards and from the 7th-9th November 2011 it was classified as a so-called Medicane, a Mediterranean Hurricane-like storm. Peak gusts up to $46 \mathrm{~m} / \mathrm{s}$ were measured (see e.g. Miglietta et al., 2013). However, during that time the cyclone was already far away from Mallorca. Fig. 3a shows the weather situation for November 8th 2011 at 0 UTC. The white solid lines represent the isobars of the mean sea level pressure whereas the colored contours are the 
Table 1

The CESAR measurement campaign took place at Palma de Mallorca between 19th October 2011 and 18 th December 2011 and it included seven periods of frequent radiosonde launches. Listed are the starting/ending dates of the periods; the release time of each radiosonde as well as the number of total and of discarded soundings per period. The different periods are denoted by $x$ in the notation in the left column of the table.

\begin{tabular}{|c|c|c|c|c|c|c|c|c|}
\hline Period P & & P1 & P2 & P3 & P4 & P5 & P6 & P7 \\
\hline \multirow[t]{3}{*}{ RS-PX-1 } & Date & 19.10 .2011 & 26.10 .2011 & 02.11.2011 & 08.11.2011 & 02.12.2011 & 10.12 .2011 & 14.12 .2011 \\
\hline & Time & 17 UTC & 17 UTC & 17 UTC & 11 UTC & 17 UTC & 23 UTC & 14 UTC \\
\hline & Height & 27.6360 & 28.7130 & 28.4360 & 29.2480 & 28.2270 & 28.7900 & 26.5530 \\
\hline \multirow[t]{3}{*}{ RS-Px-2 } & Date & 19.10.2011 & 26.10.2011 & 02.11.2011 & 08.11.2011 & 02.12.2011 & 11.12 .2011 & 14.12.2011 \\
\hline & Time & 20 UTC & 20 UTC & 20 UTC & 14 UTC & 20 UTC & 02 UTC & 17 UTC \\
\hline & Height & 24.2700 & 28.4960 & 27.6140 & 28.0050 & 28.6380 & 27.8770 & 29.2720 \\
\hline \multirow[t]{3}{*}{ RS-Px-3 } & Date & 19.10 .2011 & 26.10 .2011 & 02.11 .2011 & 08.11.2011 & 02.12 .2011 & 11.12 .2011 & 14.12 .2011 \\
\hline & Time & 23 UTC & 23 UTC & 23 UTC & 17 UTC & 23 UTC & 05 UTC & 20 UTC \\
\hline & Height & 28.6310 & 28.0090 & 18.8080 & 29.7340 & 28.3110 & 28.2430 & 28.3940 \\
\hline \multirow[t]{3}{*}{ RS-Px-4 } & Date & 20.10.2011 & 27.10.2011 & 03.11.2011 & 08.11.2011 & 03.12.2011 & 11.12 .2011 & 14.12.2011 \\
\hline & Time & 02 UTC & 02 UTC & 02 UTC & 20 UTC & 02 UTC & 08 UTC & 23 UTC \\
\hline & Height & 27.5860 & 28.4680 & 18.5920 & 23.8070 & 29.1550 & 26.7640 & 29.4320 \\
\hline \multirow[t]{3}{*}{ RS-PX-5 } & Date & 20.10 .2011 & 27.10.2011 & 03.11.2011 & 08.11.2011 & 03.12.2011 & 11.12 .2011 & 15.12 .2011 \\
\hline & Time & 05 UTC & 05 UTC & 05 UTC & 23 UTC & 05 UTC & 11 UTC & 02 UTC \\
\hline & Height & 29.1950 & 28.9560 & 28.7700 & 26.6730 & 28.0320 & 28.4080 & 29.4000 \\
\hline \multirow[t]{3}{*}{ RS-Px-6 } & Date & 20.10 .2011 & 27.10.2011 & 03.11.2011 & 09.11.2011 & 03.12.2011 & 11.12 .2011 & 15.12.2011 \\
\hline & Time & 08 UTC & 08 UTC & 08 UTC & 02 UTC & 08 UTC & 14 UTC & 05 UTC \\
\hline & Height & 29.2360 & 30.0610 & 29.9580 & 29.6120 & 28.7790 & 26.0810 & 27.9000 \\
\hline \multirow[t]{3}{*}{ RS-PX-7 } & Date & 20.10 .2011 & 27.10.2011 & 03.11.2011 & 09.11.2011 & 03.12.2011 & 11.12.2011 & 15.12 .2011 \\
\hline & Time & 11 UTC & 11 UTC & 11 UTC & 05 UTC & 11 UTC & 17 UTC & 08 UTC \\
\hline & Height & 28.6460 & 28.5680 & 28.3010 & & 28.1580 & 29.0080 & 29.2940 \\
\hline \multirow[t]{3}{*}{ RS-Px-8 } & Date & 20.10 .2011 & 27.10.2011 & 03.11.2011 & 09.11.2011 & 03.12.2011 & 11.12 .2011 & 15.12 .2011 \\
\hline & Time & 14 UTC & 14 UTC & 14 UTC & 08 UTC & 14 UTC & 20 UTC & 11 UTC \\
\hline & Height & 28.8520 & 24.6970 & 29.3930 & 29.1600 & 28.6170 & 28.4740 & 28.6600 \\
\hline RS-Px-9 & Date & 20.10 .2011 & 27.10 .2011 & 03.11.2011 & 09.11.2011 & 03.12.2011 & 11.12 .2011 & 15.12 .2011 \\
\hline & Time & 17 UTC & 17 UTC & 17 UTC & 11 UTC & 17 UTC & 23 UTC & 14 UTC \\
\hline & Height & 29.3970 & 28.6660 & 29.0810 & 29.8610 & 28.4430 & 29.0840 & 28.5340 \\
\hline RS-Px-10 & Date & 20.10.2011 & 27.10 .2011 & 03.11.2011 & 09.11.2011 & 03.12.2011 & 12.12 .2011 & 15.12.2011 \\
\hline & Time & 20 UTC & 20 UTC & 20 UTC & 14 UTC & 20 UTC & 02 UTC & 17 UTC \\
\hline & Height & 28.6960 & 28.2630 & 28.6230 & 29.0200 & 25.8490 & 27.6310 & 27.3000 \\
\hline RS-Px-11 & Date & 20.10.2011 & 27.10.2011 & 03.11.2011 & 09.11.2011 & 03.12.2011 & 12.12 .2011 & 15.12.2011 \\
\hline & Time & 23 UTC & 23 UTC & 23 UTC & 17 UTC & 23 UTC & 05 UTC & 20 UTC \\
\hline & Height & 21.8500 & 23.6790 & 28.1140 & 29.2500 & 27.0500 & 28.7550 & 29.1660 \\
\hline RS-Px-12 & Date & 21.10 .2011 & 28.10.2011 & 04.11 .2011 & 09.11.2011 & & 12.12.2011 & 15.12.2011 \\
\hline & Time & 02 UTC & 02 UTC & 02 UTC & 20 UTC & & 08 UTC & 23 UTC \\
\hline & Height & 29.5740 & 29.1210 & 24.8460 & 28.0350 & & 28.4490 & 26.1290 \\
\hline RS-Px-13 & Date & 21.10 .2011 & 28.10.2011 & 04.11.2011 & 09.11.2011 & & 12.12 .2011 & 16.12 .2011 \\
\hline & Time & 05 UTC & 05 UTC & 05 UTC & 23 UTC & & 11 UTC & 02 UTC \\
\hline & Height & 29.3950 & 29.9980 & 28.1530 & 28.6630 & & 28.6450 & 29.5890 \\
\hline RS-Px-14 & Date & 21.10 .2011 & 28.10.2011 & 04.11 .2011 & & & 12.12.2011 & 16.12 .2011 \\
\hline & Time & 08 UTC & 08 UTC & 08 UTC & & & 14 UTC & 05 UTC \\
\hline & Height & 28.3130 & 30.2940 & 30.3270 & & & 29.1650 & 17.9860 \\
\hline RS-Px-15 & Date & 21.10 .2011 & 28.10.2011 & 04.11 .2011 & & & & 16.12.2011 \\
\hline & Time & 11 UTC & 11 UTC & 11 UTC & & & & 08 UTC \\
\hline & Height & 24.7330 & 28.6280 & 29.6610 & & & & 28.3930 \\
\hline RS-Px-16 & Date & 21.10 .2011 & 28.10 .2011 & 04.11 .2011 & & & & 16.12 .2011 \\
\hline & Time & 14 UTC & 14 UTC & 14 UTC & & & & 11 UTC \\
\hline & Height & 26.2700 & 19.4030 & 28.9280 & & & & 29.6660 \\
\hline RS-Px-17 & Date & & 28.10.2011 & 04.11 .2011 & & & & 16.12.2011 \\
\hline & Time & & 17 UTC & 17 UTC & & & & 14 UTC \\
\hline & Height & & 28.8640 & 27.9070 & & & & 28.6060 \\
\hline RS-Px-18 & Date & & 28.10 .2011 & 04.11 .2011 & & & & 16.12 .2011 \\
\hline & Time & & 20 UTC & 20 UTC & & & & 17 UTC \\
\hline & Height & & 29.5830 & 25.9070 & & & & 17.5440 \\
\hline RS-PX-19 & Date & & 28.10 .2011 & 04.11 .2011 & & & & 16.12 .2011 \\
\hline & Time & & 23 UTC & 23 UTC & & & & 20 UTC \\
\hline & Height & & 30.1440 & 27.1020 & & & & 27.7460 \\
\hline RS-Px-20 & Date & & 29.10 .2011 & 05.11.2011 & & & & 16.12 .2011 \\
\hline & Time & & 02 UTC & 02 UTC & & & & 23 UTC \\
\hline & Height & & 28.1030 & 27.5710 & & & & 25.3750 \\
\hline RS-Px-21 & Date & & 29.10.2011 & 05.11.2011 & & & & 17.12.2011 \\
\hline & Time & & 05 UTC & 05 UTC & & & & 02 UTC \\
\hline & Height & & 28.8160 & 28.9680 & & & & 29.2280 \\
\hline RS-PX-22 & Date & & 29.10 .2011 & 05.11.2011 & & & & 17.12 .2011 \\
\hline & Time & & 08 UTC & 08 UTC & & & & 05 UTC \\
\hline & Height & & 29.7080 & 29.0590 & & & & 27.3170 \\
\hline RS-Px-23 & Date & & 29.10.2011 & 05.11.2011 & & & & 17.12.2011 \\
\hline & Time & & 11 UTC & 11 UTC & & & & 08 UTC \\
\hline & Height & & 29.4560 & 27.7360 & & & & 27.6520 \\
\hline RS-Px-24 & Date & & 29.10 .2011 & 05.11.2011 & & & & 17.12.2011 \\
\hline & Time & & 14 UTC & 14 UTC & & & & 11 UTC \\
\hline & Height & & 29.1230 & 29.7430 & & & & 27.3560 \\
\hline RS-Px-25 & Date & & & 05.11 .2011 & & & & 17.12 .2011 \\
\hline
\end{tabular}


Table 1 (continued)

\begin{tabular}{|c|c|c|c|c|c|c|c|c|}
\hline Period $\mathbf{P}$ & & P1 & P2 & P3 & P4 & P5 & P6 & P7 \\
\hline & Time & & & 17 UTC & & & & 14 UTC \\
\hline & Height & & & 28.3150 & & & & 29.8690 \\
\hline \multirow[t]{3}{*}{ RS-Px-26 } & Date & & & 05.11.2011 & & & & 17.12 .2011 \\
\hline & Time & & & 20 UTC & & & & 17 UTC \\
\hline & Height & & & 28.3800 & & & & 28.4780 \\
\hline \multirow[t]{3}{*}{ RS-Px-27 } & Date & & & 05.11.2011 & & & & 17.12.2011 \\
\hline & Time & & & 23 UTC & & & & 20 UTC \\
\hline & Height & & & 27.8690 & & & & 28.9550 \\
\hline \multirow[t]{3}{*}{ RS-Px-28 } & Date & & & 06.11.2011 & & & & 17.12 .2011 \\
\hline & Time & & & 02 UTC & & & & 23 UTC \\
\hline & Height & & & 28.5130 & & & & 28.2210 \\
\hline \multirow[t]{3}{*}{ RS-Px-29 } & Date & & & 06.11.2011 & & & & 18.12 .2011 \\
\hline & Time & & & 05 UTC & & & & 02 UTC \\
\hline & Height & & & 28.7350 & & & & 27.0680 \\
\hline \multirow[t]{3}{*}{ RS-Px-30 } & Date & & & 06.11.2011 & & & & 18.12 .2011 \\
\hline & Time & & & 08 UTC & & & & 05 UTC \\
\hline & Height & & & 24.1890 & & & & 28.9820 \\
\hline \multirow[t]{3}{*}{ RS-Px-31 } & Date & & & 06.11.2011 & & & & 18.12.2011 \\
\hline & Time & & & 11 UTC & & & & 08 UTC \\
\hline & Height & & & 29.9470 & & & & 28.2020 \\
\hline \multirow[t]{3}{*}{ RS-Px-32 } & Date & & & 06.11.2011 & & & & 18.12.2011 \\
\hline & Time & & & 14 UTC & & & & 11 UTC \\
\hline & Height & & & 30.4430 & & & & 29.5620 \\
\hline \multirow[t]{3}{*}{ RS-Px-33 } & Date & & & & & & & 18.12 .2011 \\
\hline & Time & & & & & & & 14 UTC \\
\hline & Height & & & & & & & 28.9070 \\
\hline \multirow[t]{3}{*}{ RS-Px-34 } & Date & & & & & & & 18.12 .2011 \\
\hline & Time & & & & & & & 17 UTC \\
\hline & Height & & & & & & & 28.6430 \\
\hline Total & & 16 & 24 & 32 & 12 & 11 & 14 & 34 \\
\hline Discarded & & 3 & 3 & 4 & 1 & 0 & 0 & 2 \\
\hline
\end{tabular}

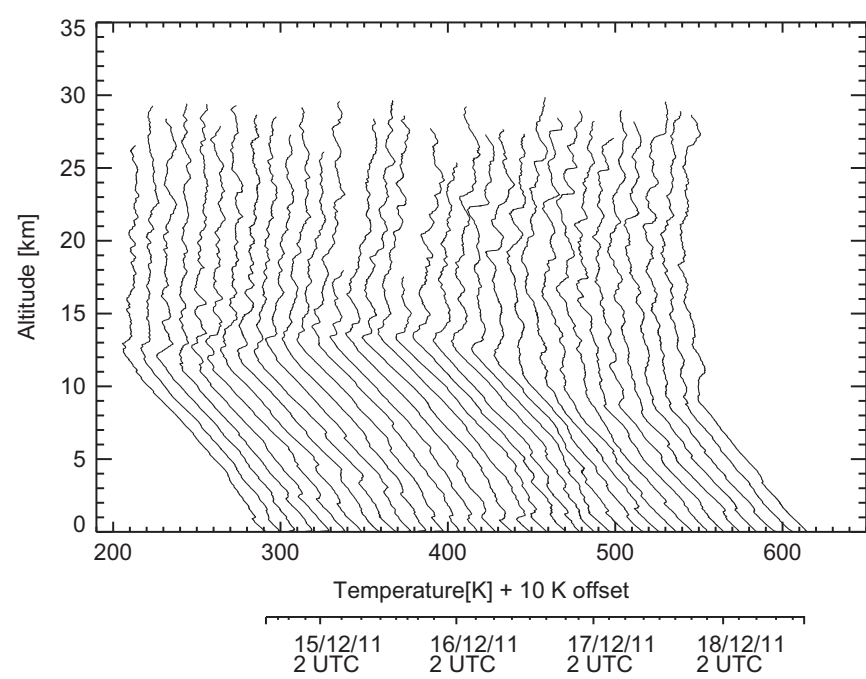

Fig. 1. Vertical temperature profiles measured by radiosondes during the observing period (P7: 14.-18.12.2011). Each subsequent profile is offset by $10 \mathrm{~K}$ from the previous profile.

equipotential temperature values at $850 \mathrm{hPa}$. The isobars on this figure show that the center of the Medicane was located in the Mediterranean Sea, east of Mallorca. The color-coded equipotential temperatures hint on the strong cyclone's rotational structure.

b. Campaign phase P7

P7 is characterized by the passage of two cold fronts. In the evening of 15th December 2011 a weak cold front reached the Balearic Island. The second one, passing Mallorca in the night from 16th to 17th December 2011, was part of the European winter storm "Joachim", which caused a lot of damage on its way through

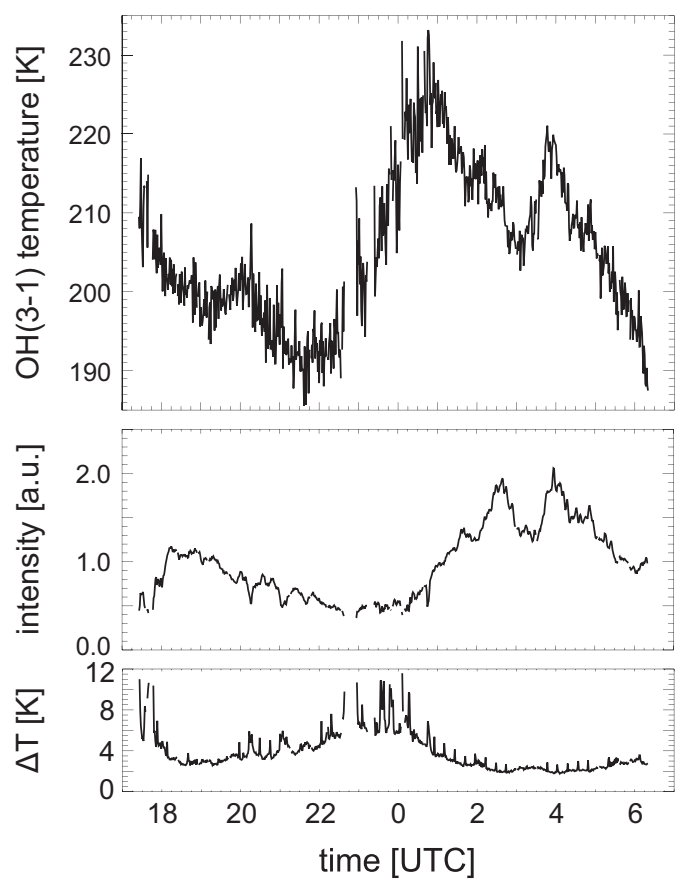

Fig. 2. Nocturnal airglow measurements of GRIPS-12 for 16.-17. December 2011 The upper panel shows the evolution of $\mathrm{OH}(3-1)$ rotational temperatures throughout the night (one minute mean values). The second panel shows the course of the respective emission intensities relative to its nightly mean. The lowest panel gives the uncertainties of the rotational temperatures. If the uncertainty increases beyond $7.5 \%$, data have been omitted (gaps). The average uncertainty amounts to $3.8 \mathrm{~K}(<2 \%)$ during this night.

Europe (see Axer et al., 2012). This second cold front was quite strong and had two convection lines, one almost corresponding to the surface front and one several hours after it. In Fig. 3b, which 

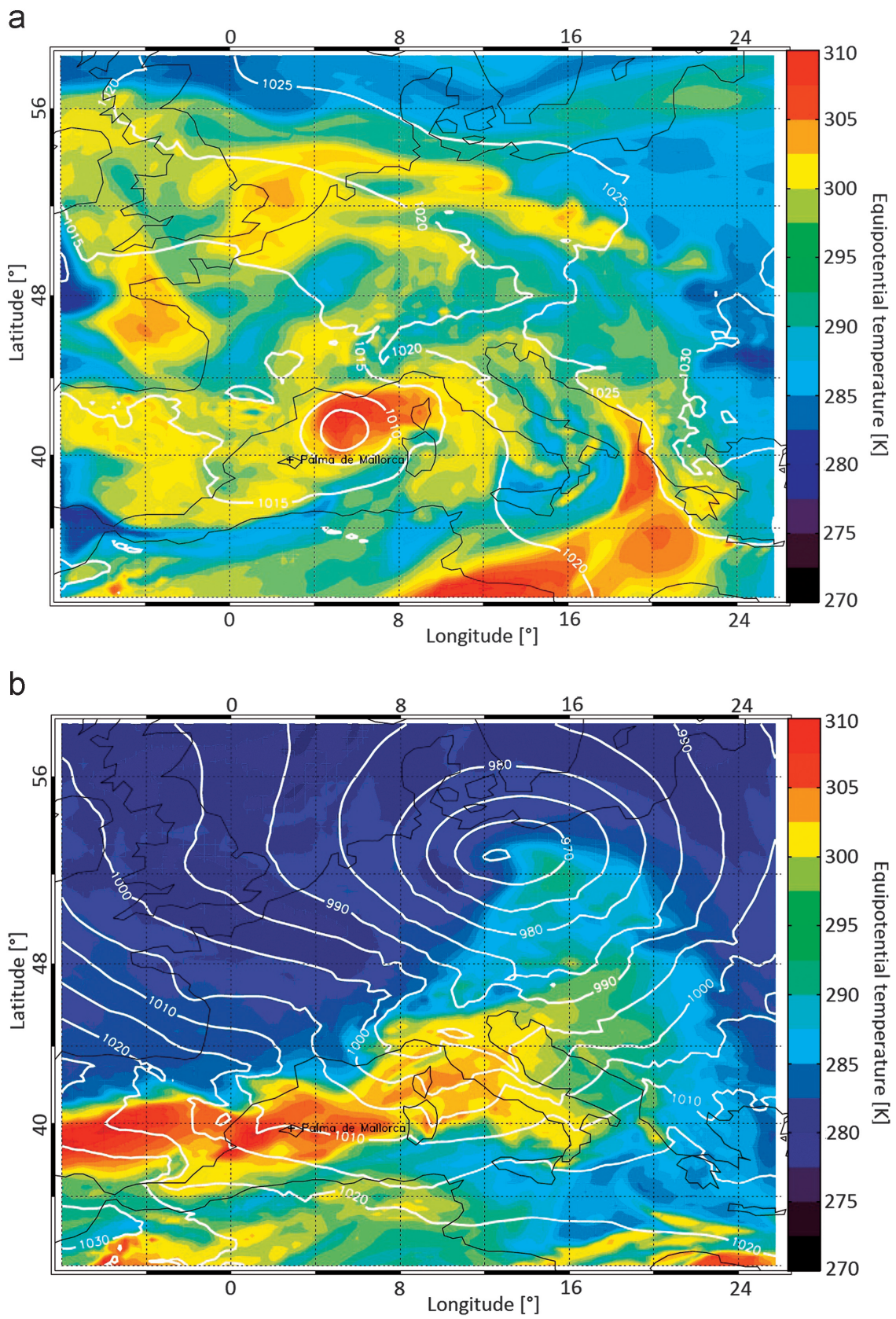

Fig. 3. Colored contour plots of equipotential temperature at $850 \mathrm{hPa}$ overlaid with isobars of mean sea level pressure (white solid lines) for 8 th November 201100 UTC (a) and 16th December 201118 UTC (b) based on ECMWF data. Details see text

presents the conditions of 16th December 18 UTC, the cold front is located northwest of Mallorca.

\section{Analysis procedure}

Vertical temperature and wind profiles derived by radiosonde measurements contain beside gravity waves, also non-gravity wave induced fluctuations which need to be properly separated before deriving GW parameters. A simple linear superposition of GW perturbations in temperature, zonal and meridional winds $\left(T^{\prime}, u^{\prime}\right.$ and $\left.v^{\prime}\right)$ on a background structure $(\bar{T}, \bar{u}$ and $\bar{v})$ is assumed: $T=\bar{T}+T^{\prime}$ (e.g. Pfenninger et al., 1999; Zhang et al., 2012). The separation of these parts is achieved by the adaptation and subtraction of a cubic spline (see Bittner et al., 1994) with vertical data spacing of $100 \mathrm{~m}$; the cut-off wavelength of the low-pass filter is chosen to be $7 \mathrm{~km}$ (see Fig. 4a). The corresponding power spectrum of vertical wavelengths is shown in Fig. $4 \mathrm{~b}$. The upper limit is used in order to focus only on mesoscale perturbations and therefore excludes the influence of, for example, planetary waves. For comparison, Vincent et al. (1997) also used a third-order polynomial fit, whereas Wang and Geller (2003) applied only a second-order polynomial for the estimation of the mean profile. The cubic spline method used here was tested regarding its capability as a filter, but the test results are not presented here in detail. Referring to these results, temperature residuals have an error bar of $+/-0.5 \mathrm{~K}$, which is of the same magnitude as the accuracy of the radiosonde itself. Wind uncertainty is $+/-0.5 \mathrm{~m} / \mathrm{s}$.

In order to derive a measure for GW activity in the stratosphere, the temperature residuals are squared and subsequently summed up for the height range $17-25 \mathrm{~km}$. This atmospheric segment is 
a

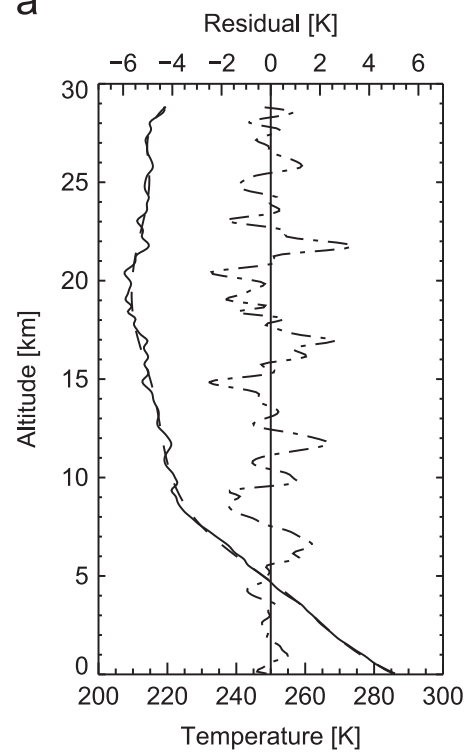

b

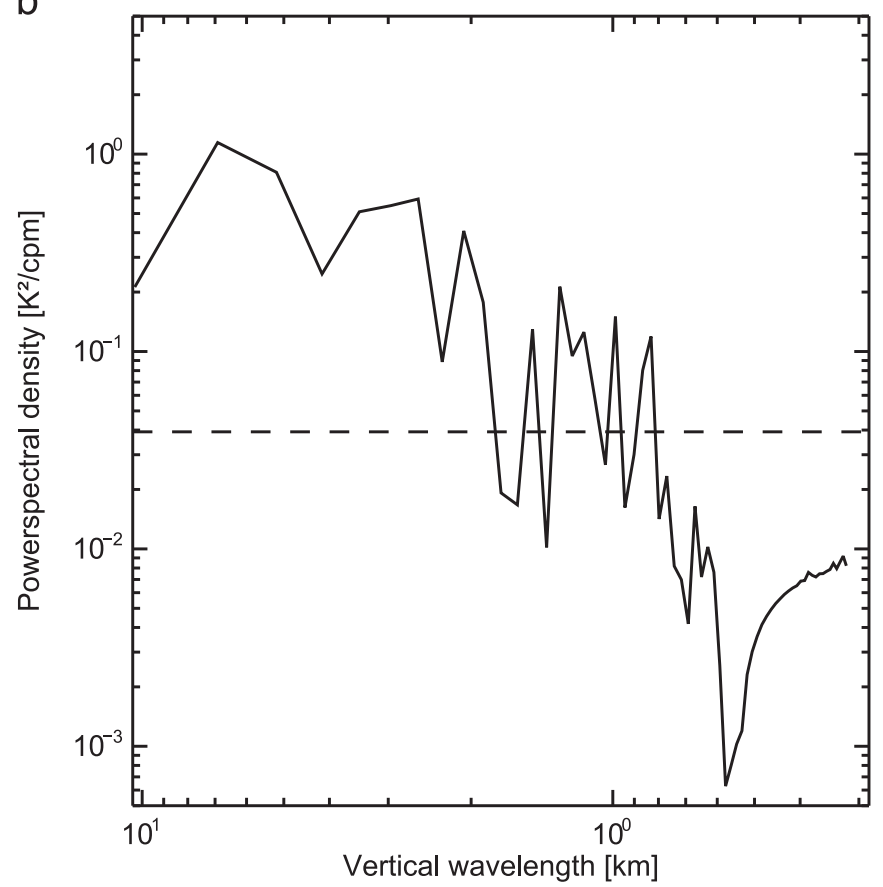

Fig. 4. (a) Vertical temperature profile (solid line) and background temperature (dashed line) as well as resulting temperature perturbations (dash-dot line) for the radiosonde released on 18th December 201114 UTC (RS-P7-33). (b) Corresponding power spectrum (FFT) of vertical wavelengths calculated from temperature perturbations. The dashed line denotes the $95 \%$ significance level of the power spectral densities.

chosen to maximize the amount of available radiosonde soundings and to minimize the effect of the tropopause on the detrending procedure described above. Owing to strong temperature gradients at tropopause height artificial signatures in the temperature fluctuations could otherwise occur. The chosen altitude range is in line with other work such as Allen and Vincent (1995), who used the height range of $17-24 \mathrm{~km}$ or Vincent and Alexander (2000) (18-25 km). Wang and Geller (2003) used 18-24.9 km.

Prior to our analysis, each radiosonde profile was checked for the maximum altitude reached. Those profiles which did not cover the whole above mentioned altitude range of interest were discarded (see also Table 1). Thus, 13 radiosondes were not used for further analysis.
The gravity-wave kinetic energy per unit mass (energy density) $E_{k}$ is defined by

$E_{k}=\frac{1}{2}\left(\overline{u^{\prime 2}}+\overline{v^{\prime 2}}+{\overline{w^{\prime}}}^{\prime 2}\right)$,

with zonal $\left(u^{\prime}\right)$, meridional $\left(v^{\prime}\right)$ and vertical $\left(w^{\prime}\right)$ wind perturbations. Overbars denote height averages. The potential energy density $E_{p}$ is given by

$E_{p}=\frac{1}{2}\left(\frac{T^{\prime}}{\bar{T}} \frac{g}{N}\right)^{2}$

where $N$ is the Brunt-Väisalä frequency, $g$ is the gravitational constant and $T^{\prime} / \bar{T}$ is the temperature fluctuation $T^{\prime}$ normalized on background temperature $\bar{T}$. The vertical velocity contribution $E_{k, w}$ can be neglected because it is much smaller than the horizontal components ( $E_{k, u}+E_{k, v}=E_{k, h} \sim 100 E_{k, w}$; e. g. Zhang et al., 2012). The Brunt-Väisalä frequency $N$ was derived from

$N^{2}=\frac{g}{\bar{T}_{0}}\left(\frac{\partial \bar{T}}{\partial \mathrm{Z}}+\frac{g}{c_{p}}\right)$.

Parameter $z$ is the vertical coordinate, $\bar{T}$ is the background temperature with initial temperature value $\bar{T}_{0}, c_{p}$ is the specific heat capacity of air at a constant pressure and $g / c_{p}=9.8 \times 10^{-3} \mathrm{~K} / \mathrm{m}$ is the adiabatic temperature gradient.

In order to approximate a time series or vertical profile or to find periods and wavelengths present in the data, harmonic analysis is applied. A linear combination of sinusoidals is adapted to the time series or vertical profile following a least squares approach. For details see Bittner et al. (1994) and Wüst and Bittner (2008).

\subsection{Gravity wave propagation direction analysis}

Wave propagation directions are investigated with two different approaches. First, a hodograph analysis is applied (e.g. Hirota and Niki, 1985; Wang et al., 2006; Wüst and Bittner, 2006). The tip of the meridional ( $\left.v^{\prime}\right)$ and zonal ( $\left.u^{\prime}\right)$ components of the wind vector for each wave describes an ellipse, where the orientation angle of its major axis indicates the horizontal propagation direction, with respect to the positive $x$-axis. Moreover, the relation of the amplitudes is equal to the intrinsic frequency $\omega$ of the wave divided by the Coriolis parameter $\mathrm{f}$ (e.g. Fritts and Alexander 2003). As the orientation of the major axis of the ellipses is between 0 and $\pi$, the horizontal propagation direction $\Theta$ has a $180^{\circ}$ ambiguity. Linear GW theory predicts that the temperature and wind perturbations $U_{\|}$are $90^{\circ}$ out of phase along the propagation direction (e.g. Vincent et al., 1997; Andrews 2010). The corresponding polarization equation is

$U_{\|}=-\frac{g}{N} \frac{T_{+90}^{\prime}}{\bar{T}}$.

Therefore, shifting all spectral components of the temperature fluctuation $T$ by $90^{\circ}$ without their amplitude being changed, the sign of $\overline{U_{\|} T_{+90}^{\prime}}$ gives the direction of propagation. This means, a positive (negative) correlation value indicates that the direction of propagation is $\Theta\left(\Theta \pm 180^{\circ}\right)$. Fig. 5 shows the normalized temperature fluctuations $T^{\prime} / \bar{T}$ (panel a), the horizontal wind fluctuations $u^{\prime}$ (panel b) and $v^{\prime}$ (panel c) as well as the corresponding hodograph (panel d) between 17 and $25 \mathrm{~km}$ altitude. The example shown in Fig. 5 is taken from the seventh period of the CESARcampaign (RS-P7-21). In Fig. 5(d) the abscissa denotes the zonal component $u^{\prime}$ and the ordinate is the meridional component $v^{\prime}$. The lower and upper height limits are denoted by a star and a triangle symbol, respectively. The resulting hodograph reveals 
a

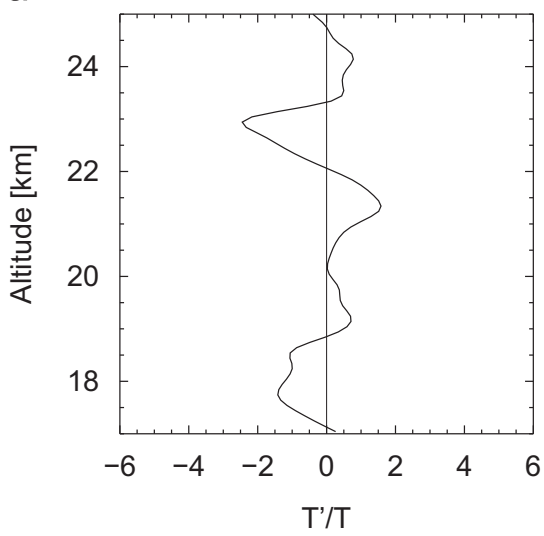

C

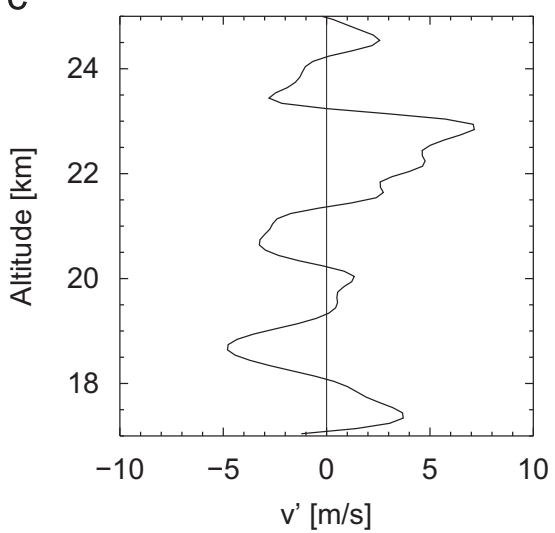

b

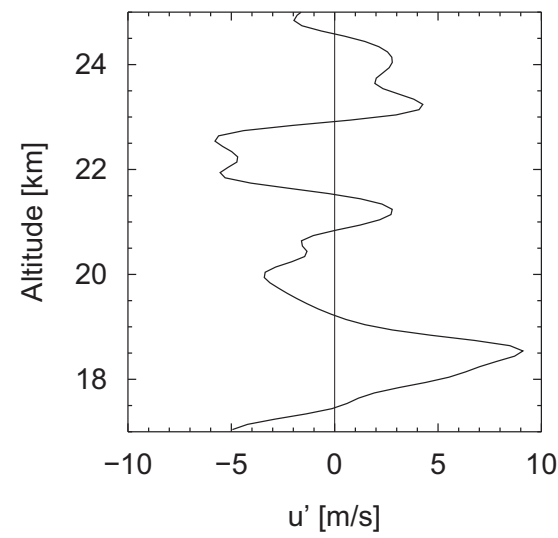

d

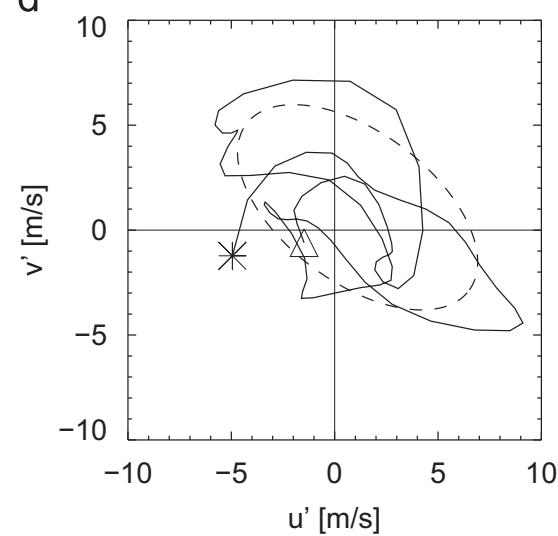

e

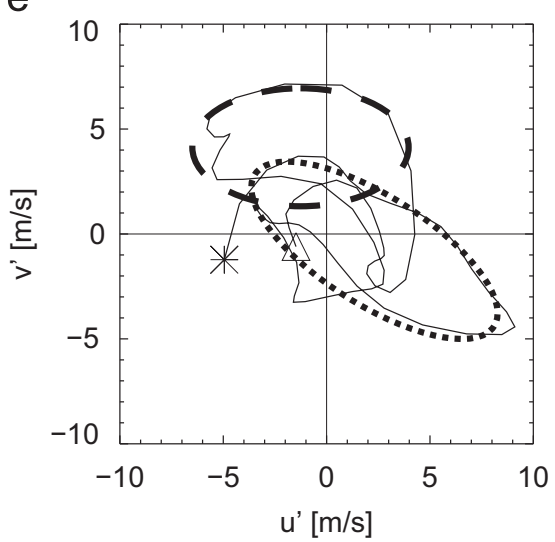

Fig. 5. Normalized temperature (a), zonal (b) and meridional (c) wind perturbations as well as hodograph of the horizontal wind perturbations (d, e) in the range of 17 to $25 \mathrm{~km}$ for 17.12.2011 02 UTC (RS-P7-21); stars and triangles denote lower and upper limit, respectively; in panel d) dashed line marks a fitted ellipse derived with leastsquare method. The hodograph obviously reveals the existence of more than one monochromatic gravity wave. It can be seen that at least two ellipses can be formed, one in the lower part ( $\sim 22-25 \mathrm{~km}$, dotted ellipse panel e) and one in the upper part ( $\sim 19-21 \mathrm{~km}$, dashed ellipse panel e) of the atmosphere, each one with different orientation.

elliptical wave-induced velocity 'spirals' as a function of height (e.g. Eckermann, 1996). The dashed line in Fig. 5d denotes the fitted ellipse to this hodograph. Fig. 4b obviously reveals the existence of more than one monochromatic gravity wave (compare also e.g. Tsuda et al., 1991; Hines, 1991). It seems that the fluctuations contain a superposition of at least $2-4 \mathrm{GWs}$, which is confirmed by applying a Fast Fourier Transformation to the temperature fluctuations. As written above, Fig. 4b shows that not only one monochromatic wave is included in this signal. At least two different ellipses can be formed in Fig. $5 d$, one in the upper part $(\sim 22-25 \mathrm{~km})$ and one in the lower part $(\sim 19-21 \mathrm{~km})$ of the atmosphere, each one with different orientations (Fig. 5e). Such kind of analysis has been performed successfully, for example, by Wüst and Bittner (2006) to study non-linear wave-wave interactions (triads). Therefore, in the presence of more than one wave, hodograph analysis can give only some statistical estimate of the dominant direction of horizontal propagation of the wave field, if one fits only one ellipse to the data of the entire vertical profile. Deriving horizontal propagation directions for single monochromatic waves, as it was performed by Wüst and Bittner (2006), is a time consuming and delicate method which can be applied only on small data sets and this is not feasible here. We performed some case studies to compare the dominant direction of horizontal propagation and the individual directions of single monochromatic waves. For the example given in Fig. 5d a dominant propagation direction of $143^{\circ}$ (directions measured counterclockwise 
from east) was derived, whereas the mean of the directions from the individual monochromatic waves (Fig. 5e) is $155^{\circ}$. It turns out that applying the hodograph analysis on the whole profile can be used to statistically estimate a mean gravity wave propagation direction.

Moreover, the hodograph exhibits the energy transport of a wave with altitude. In the Northern Hemisphere clockwise rotation is consistent with a monochromatic gravity wave with upward energy propagation, whereas anticlockwise rotation is identified with downward energy propagation (e.g. Hirota and Niki, 1985; Tsuda et al., 1990).

Another approach to derive predominant horizontal propagation directions in gravity wave fields is based on Stokes analysis. This technique is commonly used to determine the state of polarization of electromagnetic waves from observations. In $1852 \mathrm{G}$. Stokes introduced a set of parameters to describe the polarization of electromagnetic waves (for detailed aspects see for example Kyle, 1993). In analogy to this set of parameters describing electromagnetic waves, the so-called Stokes parameters were adapted to gravity waves by Vincent and Fritts (1987). The method, which has been applied to studies of wave motions in the mesosphere (e.g. Vincent and Fritts, 1987) and stratosphere (e.g. Eckermann and Vincent, 1989), defines the four Stokes parameters

$I=\overline{u^{\prime 2}+v^{\prime 2}}$,

$D=\overline{u^{\prime 2}-v^{\prime 2}}$

$P=\overline{2 u^{\prime} v^{\prime}}$,

$Q=\overline{2 u_{+90}^{\prime} v^{\prime}}$.

Overbars denote height averages and $u^{\prime}$ and $v^{\prime}$ are the amplitudes of the zonal and meridional wind fluctuations, respectively. The variable $u_{+90}^{\prime}$ is the $90^{\circ}$ phase shift of $u^{\prime}$. In optical terms, $I$ is the throughout parameter, $D$ is the throughout anisotropic parameter, $P$ is the linear polarization parameter and $Q$ is the circular polarization parameter. The polarization ellipse of the wave motion is composed by mapping the motion of the vector of deviation. The resulting orientation of the major axis of the ellipse

$\Theta=\frac{1}{2} \arctan (P / D)$,

can be calculated with the Stokes parameter and has a $180^{\circ}$ ambiguity as well, which can be solved as described above. Analysis of profiles which contain more than one wave is clearly more suited to the Fourier domain. As Vincent and Fritts (1987) pointed out that the Stokes parameters might be calculable in the Fourier domain, Eckermann and Vincent (1989) investigated this possibility and developed the technique. This technique is used to derive horizontal propagation directions as well.

\subsection{Gravity wave momentum flux analysis}

Momentum flux is a prominent quantity for studying middle atmosphere dynamics. Radiosonde sounding allows estimating the horizontal momentum flux of the measured waves by retrieving temperature amplitude and vertical wavelengths of individual monochromatic gravity waves. The $\mathrm{x}$ - and $\mathrm{y}$-components of the vertical flux of horizontal momentum are (see e.g. Fritts and Alexander, 2003)

$\left(F_{p x}, F_{p y}\right)=\bar{\rho} \delta_{-}\left(\overline{u^{\prime} w^{\prime}}, \overline{v^{\prime} w^{\prime}}\right)$.

The weighting function $\delta_{-}=1-\frac{f^{2}}{\omega^{2}}(10 \mathrm{a})$ accounts for the fact that high frequency waves are more effective in transporting momentum (Fritts and Vincent, 1987), where $f=2 \Omega \sin (\phi)$ is the Coriolis parameter and $\omega$ the intrinsic frequency. $\left(u^{\prime}, v^{\prime}, w^{\prime}\right)$ is the vector of wind perturbations and $\bar{\rho}$ is the background density. Overbars denote an average over a chosen height range (here: 17$25 \mathrm{~km}$ ). It must be noted that this equation is valid if gravity waves conserve wave momentum flux, which is the case when they propagate without dissipation through a background atmosphere that varies only in the vertical. As the vertical velocity perturbation $w^{\prime}$ is not available from radiosonde measurements, estimates of the momentum fluxes can be made, if gravity wave polarization relations between $u^{\prime}, w^{\prime}$ and $T^{\prime}$ are used (compare e.g. Andrews, 2010). Then the vertical fluxes can be rewritten as follows (compare e.g. Vincent and Alexander, 2000; Gong et al., 2008):

$\left(F_{p x}, F_{p y}\right)=\bar{\rho}\left(1-\frac{f^{2}}{\omega^{2}}\right)\left(-\frac{\omega g}{N^{2}} \frac{\overline{u^{\prime} T_{+90}^{\prime}}}{\bar{T}},-\frac{\omega g}{N^{2}} \frac{\overline{v^{\prime} T_{+90}^{\prime}}}{\bar{T}}\right)$

assuming that wave-energy flux is upward. The variable $T_{+90}^{\prime}$ is the $90^{\circ}$ phase shift of $T^{\prime}$. Overbars again denote an average over a chosen height range. Then the total vertical flux of horizontal momentum due to GWs is

$F_{p h}=\sqrt{F_{p x}^{2}+F_{p y}^{2}}$.

As mentioned above, most observations include not only one monochromatic wave; they include several superposed quasimonochromatic waves with different wave parameters. Consequently, the whole spectrum of GWs needs to be distilled from each measured temperature and wind profile. One possibility to do this would be to apply spectral and hodograph analysis to each profile individually (see e.g. Wüst and Bittner, 2006). However, this procedure is rather time consuming and delicate and not feasible if one has to handle many measurements as is the case in this study (143 radiosondes). Therefore, another approach suggested by Vincent et al. (1997) is tried here. So, the product of intrinsic frequency and weighting function (10a) $\omega \delta_{-}$may be replaced by the spectral average value $\bar{\omega}$, where

$\bar{\omega}=N \frac{(p-1)}{(2-p)}\left(\frac{f}{N}\right)^{p-1}\left(1-\left(\frac{f}{N}\right)^{2-p}\right)$ for $p \neq 2$

$\bar{\omega}=-f \ln \frac{f}{N} \quad$ for $p=2$.

Parameter $p$ is the exponent from the intrinsic frequency spectrum of horizontal motions that has the form $S(\omega) \sim \omega^{-p}$ (compare Fritts and Lu, 1993). We calculated the mean verticalwavenumber power spectra of the temperature perturbations for all 143 soundings during the measurement campaign at Mallorca using a Fast Fourier Transformation. In Fig. 6 the black solid curve represents the power spectrum for the stratospheric altitude range. The spectral parameter of $-5 / 3$ one would expect for the inertial subrange (e.g. Fritts and vanZandt, 1993; Vincent et al., 1997; Wang et al., 2005), which is chosen for this study, is plotted as a black straight line in Fig. 6. The spectrum shown clearly reveals that the definition of the parameter $p$ is rather delicate as at least three different slopes are obvious. These slopes resemble the sub-ranges of the turbulence theory (compare e.g. Thrane, 1992) and thereby indicate a detailed analysis of the spectrum and the slopes. Splitting the stratospheric power spectrum in three parts and applying a regression to them, three slopes are found. Different ranges of the three parts are checked as exemplarily shown in Fig. 6. The slopes are 0.7 (dotted), 1.5 (dashed) and 3.1 (dashdotted) for $S(\omega) \sim \omega^{-p}$ with an average of 1.76 . Beside the fact that the average of the three different slopes lies between 1 and 2, each parameter $p$ has an uncertainty $(p \pm \varepsilon)$, which is on average 0.07 and important for the calculation of momentum fluxes. Moreover 


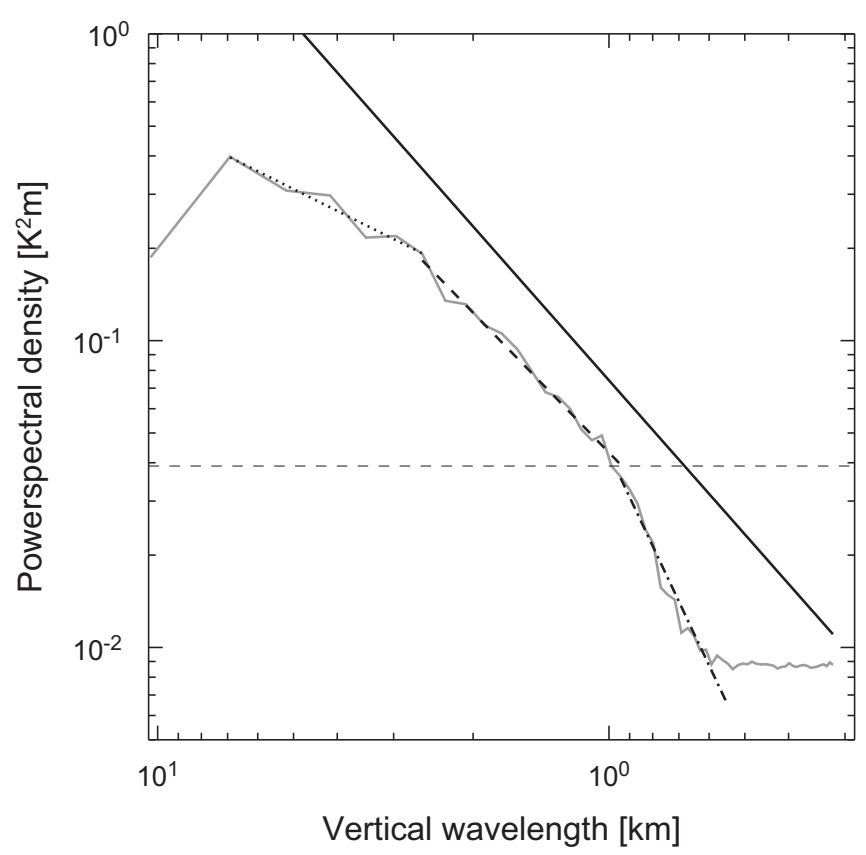

Fig. 6. Mean power spectrum of vertical wavenumber for the whole campaign data set (143 profiles), based on Fast Fourier Transformation; grey solid line indicates the stratospheric altitude range. The three black lines mark regression fits, with inclination of 0.7 (dotted), 1.5 (dashed) and 3.1 (dash-dotted) for $S(\omega) \sim \omega^{-\mathrm{p}}$ with an average of 1.76 . The horizontal dashed line denotes the $95 \%$ significance of the power spectral densities.

we estimated the significance of the power spectral densities, which is marked by the dashed line in Fig. 6. Regarding to this limit, only vertical wavelengths greater than $1 \mathrm{~km}$ are significant.

\section{Results and discussion}

\subsection{Temperature fluctuations}

Fig. 7a shows the height dependent temperature fluctuations in Kelvin as function of time, which were extracted from the detrended radiosondes profiles. It is remarkable that the tropopause region is characterized by varying negative values $(-10$ to $-2 \mathrm{~K}$ ) ranging between 9 and $14 \mathrm{~km}$ height during the campaign time period. This effect can be explained by the fact that the curvature of the vertical temperature profile at the tropopause is strongly variable in time and height as mentioned above. The stronger the curvature is, the less a spline with a given number of sampling points used for detrending in this work, can reproduce this feature. This feature therefore reflects an artifact and must be omitted from further scientific analysis. We thus only analyzed residuals from heights above $17 \mathrm{~km}$. However, this artifact may be used in order to get an impression about the variability of the tropopause height itself (and thus for characterization of meteorological situations etc.). The temporal intervals P1 and P2 show a tropopause height of around $12 \mathrm{~km}$. A pronounced variability in tropopause height during P3 and P4 is likely due to the approaching Medicane, whereas P6 clearly exhibit a comparatively low variability of temperature fluctuations with altitude. P5 looks similar to P4. The first part of the period is characterized by tropopause height of around $10 \mathrm{~km}$, whereas the second part shows signals at $13-14 \mathrm{~km}$ altitude. Finally, P7 is characterized by a strong tropopause temperature extremum during the first half of the ascents and a less developed one during the second half.

Fig. 7a also reveals two periods of pronounced gravity wave activity in the stratosphere, which are marked with black rectangles. It seems that both phases of pronounced GW activity in the stratosphere correspond to a decreasing tropopause height, which, in turn, indicates changing weather situations. For this reason further investigations of P3 and P7 are performed in the following sections.

\subsection{Comparison between gravity wave activity, wind and pressure}

In Fig. $7 \mathrm{~b}$ the time series of the ground pressures at Palma de Mallorca (lower panel), of the background wind speeds (middle panel) and of the stratospheric GW activity proxy (GWA; upper panel) are shown for the whole campaign time period. There appears to be a correlation in the variations of these three parameters, namely low ground pressure, strong tropospheric wind speeds and enhanced stratospheric GWA, especially during the two time intervals of strong cyclone and frontal activity (P3, P7). During these two periods the stratospheric GWA reaches $326 \mathrm{~K}^{2}$ (05.11.2011, 05 UTC; RS-P3-21) and 620 K² (17.12.2011, 02 UTC; RSP7-21) at its maximum. Enhanced background wind speed and low ground pressure appear slightly shifted prior to the abovementioned maxima in GWA. Black solid lines are drawn in Fig. 7b to guide the eye. The dash dotted line in P7 is drawn, because the GWA peak marks gravity waves that could be associated with the first of the two convection lines of the cold front on November 16/ 17 2011. Maximum wind speeds and minimum pressure were observed during the passage of the second convection line some hours later.

In addition to the phases of enhanced signals, a kind of background GWA exists all of the remaining time. In average the GWA is about $135 \mathrm{~K}^{2}$, calculated by the arithmetic mean of the campaign period. Topographic gravity waves, excited by the prevailing wind direction (west, so-called "Poniente") at Mallorca and the mountain range in the northwestern part of the island could explain this phenomenon.

As the horizontal background wind is correlated with the ground pressure gradient (geostrophic wind approximation) and often can give an indication of approaching fronts tropospheric wind speeds are analyzed with regard to GWA. In other work (not shown here) we analyzed a time series covering 13 years (19972009) of four times per day radiosonde launches in Prague. We found evidence for a correlation between a pronounced decay of ground pressure near the center of a cyclone and enhanced GWA in the lower stratosphere. Increased wind speeds in the upper troposphere were found as a consequence of pronounced ground pressure drop. As high wind speeds are due to a strong pressure gradient (gradient wind), which can often be found between the warm and cold front of an extratropical cyclone, the observation of high wind speeds can give an indication of approaching frontal systems. The convective regions of the cyclone (center and fronts) can radiate gravity waves (see peaks in GWA in Fig. 7b), while on the other hand high jet wind speeds can filter them. Moreover, cyclone induced influence of the jet stream (enhancement/weakening) can lead to a stronger/weaker wind shear. In case of increased wind shear pronounced gravity wave radiation can occur on the other hand. In case of decreased wind shear vertically propagating gravity waves are less filtered.

Two aspects of our results must be mentioned. First, there is some time shift between the peak signatures of the three parameters in Fig. 7b. This time shift amounts to about $24 \mathrm{~h}$ between ground pressure and GWA. Secondly, the GW signatures are mostly not present over more than six hours. Assuming that the fronts/ cyclones are the GW sources, this could be interpreted in terms of 

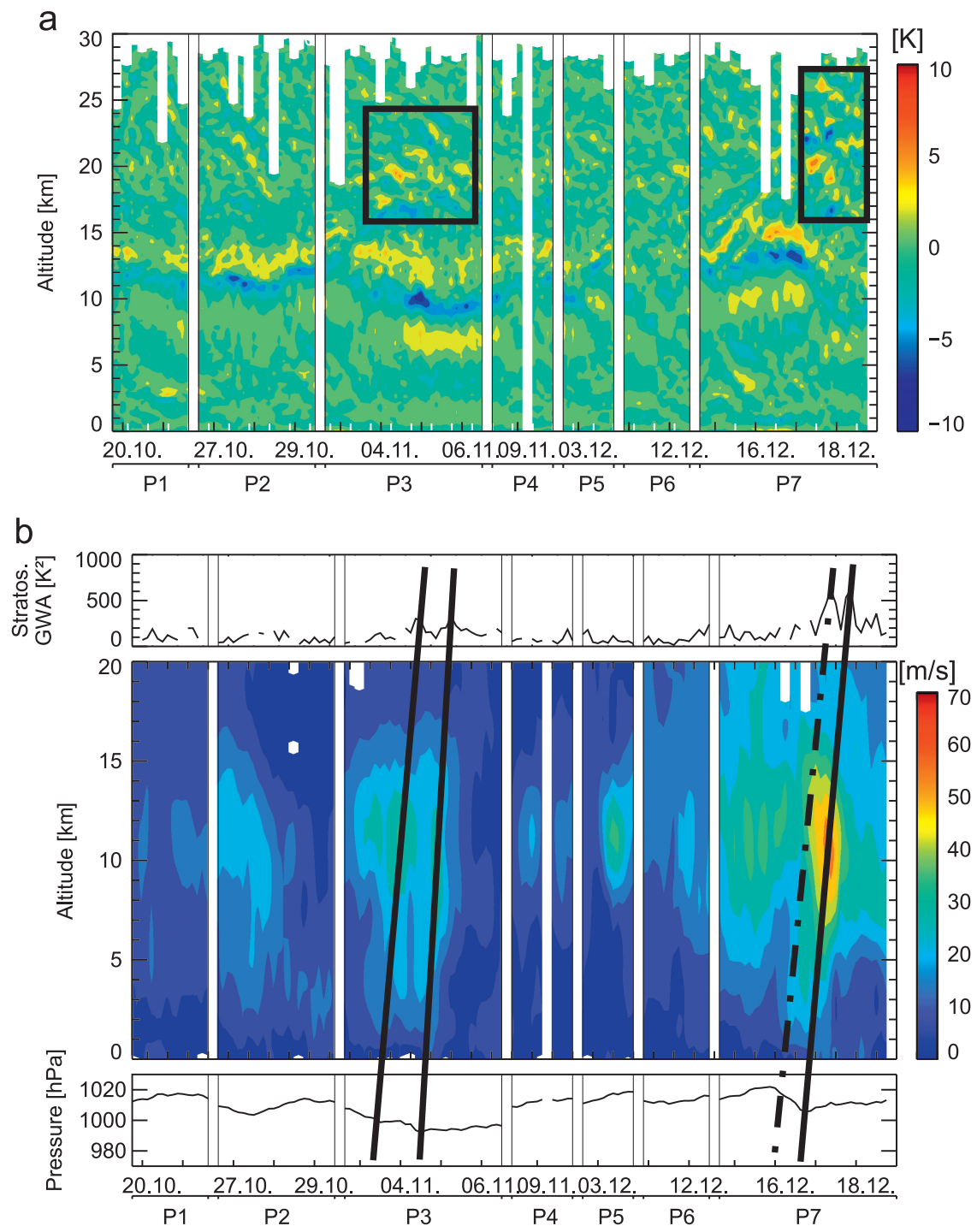

Fig. 7. (a) Temperature perturbations in Kelvin varying with height and time during the whole campaign time period at Mallorca: black rectangles mark regions of enhanced gravity wave activity. (b) Time series of surface pressure (hPa; lower panel), horizontal background wind speed (m/s; middle panel) between 0 and $20 \mathrm{~km}$ altitude and stratospheric gravity wave activity ( $\mathrm{K}^{2}$; upper panel) for measuring campaign at Mallorca: solid lines (to guide the eye) denote a possible correlation between these three parameters, whereas the dash-dotted line marks a correlation even if wind speed and pressure do not have peak values. This can be attributed to the first of two convection lines of the cold front at November 16th/17th 2011.

a non-isotropic GW radiation by the front/cyclone in each direction. This is in accordance with modeling studies (Piani et al., 1999; Alexander et al., 2004). Moreover, a low-pressure system can lead to a destabilization of the troposphere resulting in a worsening of the propagation conditions of GWs. Despite filtering processes and wave breaking, convectively radiated waves due to a cyclone could reach lower stratospheric levels. Beside the possibility of waves with phase speeds that are opposite to or greater than the background wind speed (see Section 5.4), the main reason that waves reach the stratosphere, could be the altitude of their source. Static stability theory indicates that the higher the source is located in the troposphere, the more waves could reach the lower stratosphere.

\subsection{Horizontal propagation}

Using two different methods, Stokes parameter and hodograph analysis, horizontal gravity wave propagation directions are derived. Fig. 8 shows the main horizontal propagation directions of all gravity wave signatures between 19th October 2011 and 18th December 2011 in the lower stratosphere, calculated with the hodograph (a) and the Stokes parameter analysis (b). The horizontal propagation directions of the gravity waves are sorted in $30^{\circ}$-sectors. Shaded areas indicate the frequency of occurrence for each segment as derived from the 143 detrended radiosonde profiles. Even though Stokes parameter analysis yields a slightly more isotropic pattern of propagation directions compared to hodograph analysis, the results of both methods agree well showing that northern and southeastern directions are predominant propagation directions (marked by the bold black lines in Fig. 8).

In order to understand the preferential horizontal propagation directions, it is interesting to look at the main wind directions at Mallorca. The so-called "Poniente" is a warm westerly wind from the Spanish mainland and is sometimes replaced by the so-called "Levante" (a warm easterly wind developing over the Mediterranean Sea close to the North African coast). The Poniente-wind has to cross the mountain range of Mallorca (Serra de Tramuntana). Through the prevailing wind direction and the alignment of the "Serra de Tramuntana", most convection passes Mallorca from northwest to southeast. Fig. 9 shows the horizontal propagation directions before (a) and after (b) the cold front (P7) passed 
a

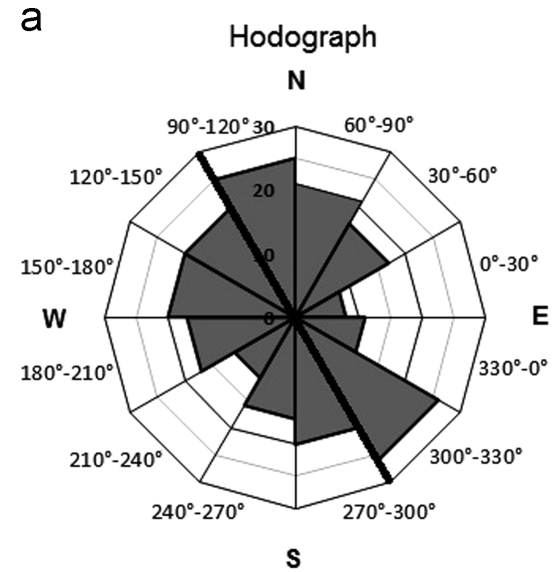

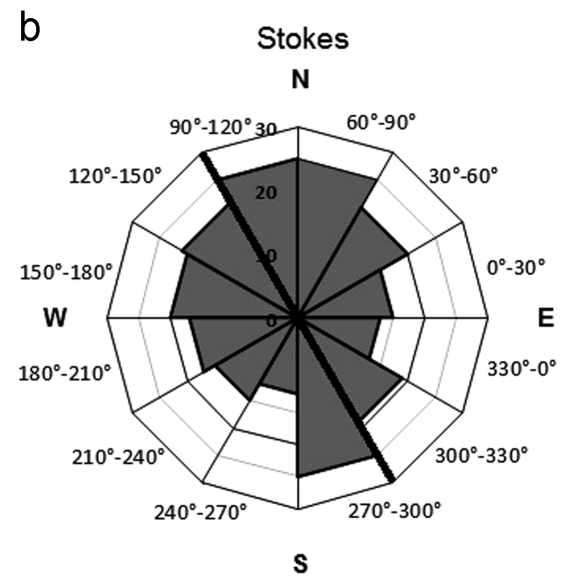

Fig. 8. Statistics of horizontal propagation directions of the gravity waves observed during the radiosonde campaign at Mallorca: (a) Results of hodograph analysis. (b) Results of Stokes parameter analysis.

Mallorca. The graphic clearly reveals that the observed preferred directions of the measured gravity waves are in line with the prevailing wind directions and the corresponding directions of crossing convection, which is interpreted as a possible gravity wave source. The gravity waves are generated through vertical displacements in the atmosphere and therefore propagate away from their source (note: the propagation direction has a vertical and a horizontal part). Especially, GWs radiated from convective lines at fronts propagate horizontally almost perpendicular to the orientation of the front. This means on the one hand that gravity waves with southeast horizontal propagation directions can only be observed at Palma de Mallorca when the convective source has not yet passed the measurement site. On the other hand, northwestern directions could be derived from the measurements when the source has already passed Palma de Mallorca. We therefore interpret our results in the way that the preferred horizontal propagation directions to northwest and southeast are associated with prevailing wind directions and convection. This finding is in good agreement with previous studies of convectively (e.g. Piani et al., 1999; Alexander et al., 2004; Lehmann et al. 2012) and topographically (Preusse et al., 2002; Sato et al., 2011) generated gravity waves.

\subsection{Gravity wave activity observed in the middle atmosphere}

As mentioned above, in the night of 16th-17th December 2011 a strong cold front with two corresponding convection lines passed
Mallorca (see Section 3, P7). Though clouds can prevent the observation of airglow emission from the upper mesosphere with the GRIPS 12, two nearly cloud free nights (16./17.12. and 17./18.12.2011) allowed the recording of airglow temperature time series. Thus, a comparison of the temperature variability in the lower stratosphere and in the upper mesosphere was performed in order to look for corresponding features. The upper part of Fig. 10 shows the GRIPS 12 temperatures of these two nights, whereas the lower plot displays the temperature fluctuations derived from the radiosonde soundings. During the time interval of the frontal passage, which is illustrated by the black rectangle, the amplitudes of the temperature fluctuations in the lower stratosphere are moderate while the mesopause temperature strongly increases. Pronounced gravity wave activity appears in the lower stratosphere after the frontal passage; black dotted lines to guide the eye denote the wave fronts and dash-dotted lines the propagation direction of the waves (perpendicular to their wave fronts). The distance between the phase lines yields vertical wavelengths of $6-7 \mathrm{~km}$.

The harmonic analysis was also applied to the temperature and wind residuals of the radiosonde soundings, which took place between 16th December 14 UTC and 18th December 14 UTC. Several vertical wavelengths were found as the power spectrum in Fig. 4(b) reveals. For the majority of soundings a vertical wavelength between 6 and $7 \mathrm{~km}$ was derived. Besides these a lot of smaller wavelengths were also deduced. Comparing the wave parameters from spectral analysis and the ones which we derived by eye from Fig. 10, it becomes clear that a wave with vertical wavelength of $6-7 \mathrm{~km}$ is a

Before: 16.12.2011

$\mathrm{N}$

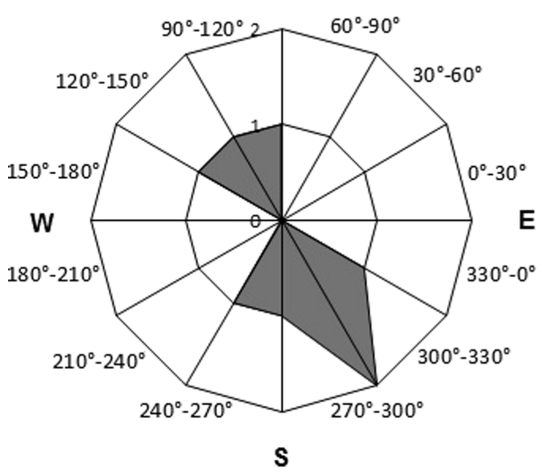

b

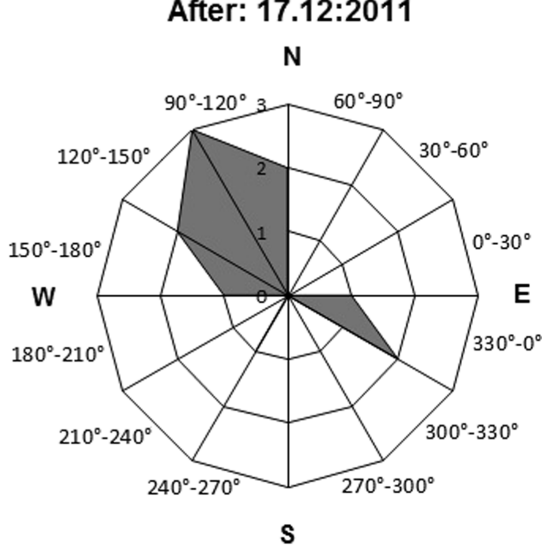

Fig. 9. Statistics of horizontal propagation directions of the gravity waves observed before (a) and after (b) the passage of a cold front during the night of 16 th to 17 th December 2011. Results are based on hodograph analysis. 


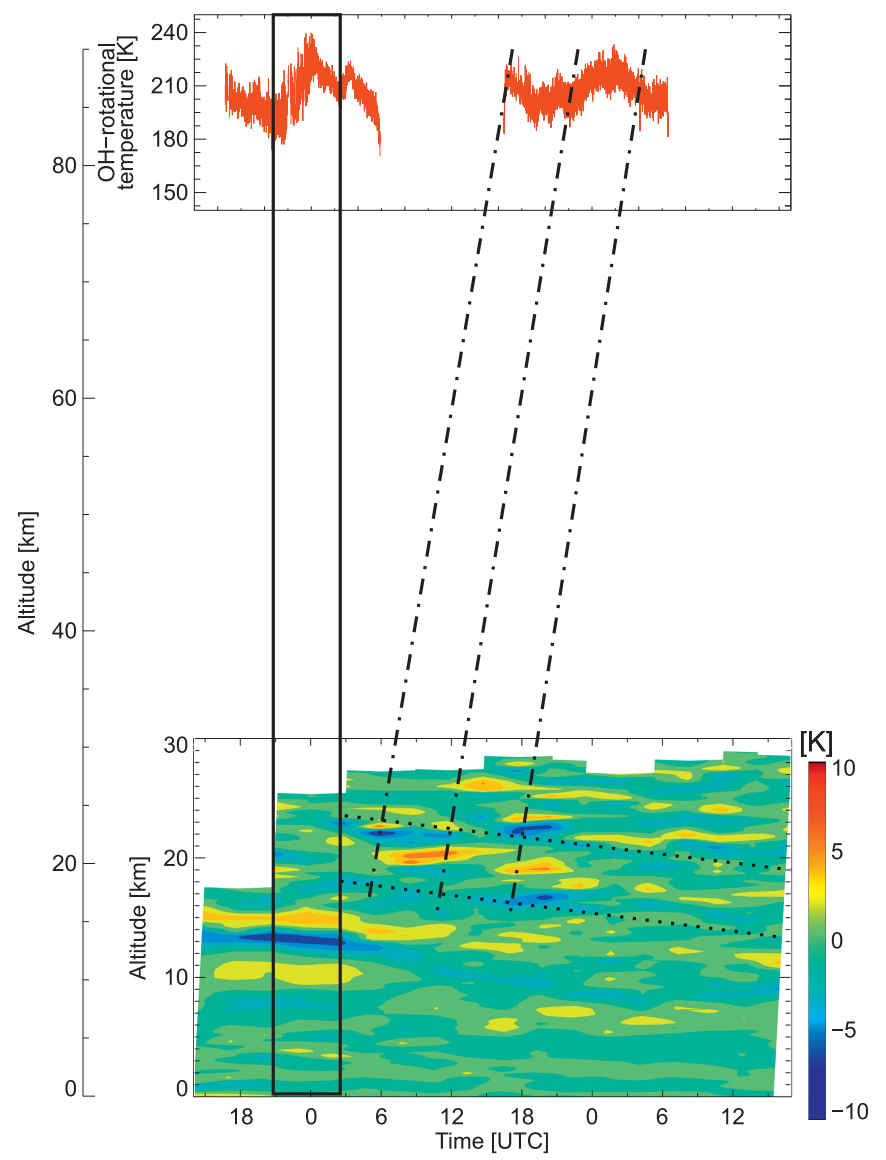

Fig. 10. Upper part: GRIPS mesopause temperatures for the nights from 16th to 17th December 2011 and 17th to 18th December 2011; lower part: temperature perturbations; the black rectangle marks the time range of a strong cold front, the dotted lines as well as dash-dot lines are fitted by hand and denote wave fronts and wave propagation directions, respectively.

present in the lower stratosphere. Waves of different vertical wavelengths are less obvious. Taking the error bar of the temperature and wind residuals into account, amplitudes lower than $0.5 \mathrm{~K}$ and $0.5 \mathrm{~m} / \mathrm{s}$ are not reliable. Then intrinsic frequencies, horizontal propagation directions, horizontal wavelengths, horizontal and vertical group as well as phase speeds were derived (see Table 2).

Mesopause temperatures of the night from 17th to 18th December are also analyzed for gravity waves using the harmonic analysis method. Four sinusoids with periods ranging between approximately $1.5 \mathrm{~h}$ and $10 \mathrm{~h}$ were found. The instrument covers different $\mathrm{OH}$ airglow vibrational transitions $\mathrm{OH}(3-1)$ and $\mathrm{OH}(4-$ $2)$ ), which originate from slightly different altitudes. A comparison of these emissions reveals that the waves recorded in the mesosphere are also propagating upwards.

The time delay between the two different emissions can also allow for an estimation of vertical wavelengths. However, precise results are only obtained for the $10 \mathrm{~h}$ period, which has the highest amplitude. The corresponding vertical wavelength is found to be approximately $7 \pm 2.3 \mathrm{~km}$. Although there is no definite evidence, that the oscillations observed in the upper mesosphere are identical to those in the lower stratosphere, the agreement in time of occurrence and vertical wavelength is remarkable for this night.

To fill the gap between radiosonde soundings in the stratosphere and GRIPS measurements in the mesopause, temperature profiles of the satellite mission TIMED/SABER (Thermosphere Ionosphere Mesosphere Energetics Dynamics/Sounding of the Atmosphere using Broadband Emission Radiometry; for details see http://saber.gats-inc.com) were filtered for temporal and spatial
Table 2

Gravity wave parameters based on results of harmonic analysis for vertical wavelengths of $6-7 \mathrm{~km}$.

\begin{tabular}{ll}
\hline Wave parameter & Range \\
\hline Intrinsic frequency & $4.0 \mathrm{E}-041 / \mathrm{s}-6.0 \mathrm{E}-041 / \mathrm{s}$ \\
Horizontal wavelength & $117 \mathrm{~km}-162 \mathrm{~km}$ \\
Vertical group velocity & $0.9 \mathrm{~m} / \mathrm{s}-1.5 \mathrm{~m} / \mathrm{s}$ \\
Horizontal group velocity & $24.0 \mathrm{~m} / \mathrm{s}-25.5 \mathrm{~m} / \mathrm{s}$ \\
Zonal phase speed & $-11.6 \mathrm{~m} / \mathrm{s}--4.9 \mathrm{~m} / \mathrm{s}$ \\
Time period for $65 \mathrm{~km}$ & $12 \mathrm{~h}-20 \mathrm{~h}$ \\
Period & $113 \mathrm{~min}-764 \mathrm{~min}$ \\
Vertical propagation direction & Upwards \\
Horizontal propagation direction & $119^{\circ}-172^{\circ}$ \\
\hline
\end{tabular}

match. Two matching profiles were found (16.12.2011 19:20 UTC and 18.12.2011 01:40 UTC). After extracting the GW signatures with the explained detrending method (cutoff vertical wavelength was $20 \mathrm{~km})$, two defined atmospheric segments $(18-50 \mathrm{~km}$ and 52-87 km) were analyzed with harmonic analysis. For the first profile vertical wavelengths of 6-7 km were found in both height segments, whereas this is not the case for the second profile. This can be explained by the fact that the first profile was directly located next to the front whereas the second profile was measured with a large distance to it.

It is well known that GWs are strongly influenced by the environment through which they propagate. Thus, wave propagation often differs from what linear wave theory predicts, because waves are reflected in the vertical or influenced by wave-wave interaction (e.g. Fritts et al., 2006). Therefore, it is necessary to investigate phase speeds and horizontal background winds to ensure whether upward propagation from the troposphere to the mesopause region is possible. The zonal phase speeds due to the $6-7 \mathrm{~km}$ waves are found to range between $\sim-12 \mathrm{~m} / \mathrm{s}$ and $\sim 14 \mathrm{~m} / \mathrm{s}$ during 17 th to 18th December. As zonal background wind speed $\mathrm{u}_{0}$ can filter gravity waves $\left(\mathrm{c}<\mathrm{u}_{0}\right)$ zonal wind speeds at Palma de Mallorca for four time steps (17.12.2011 0, 6, 12 and 18 UTC) based on ECMWF (European Centre for Medium-Range Weather Forecasts)-data are compared to GW zonal phase speeds. The comparison shows that the GWs derived above Mallorca could have propagated from their tropospheric source into the mesopause region.

Taking all these results into account, we tentatively speculate that a gravity wave with $\lambda_{\mathrm{z}} \approx 6-7 \mathrm{~km}$ might have propagated vertically from the lower stratosphere up to the upper mesosphere. Such finding is not unusual. For example, Suzuki et al. (2013) have shown similar results.

\subsection{Energy densities and momentum fluxes}

To investigate energy transport and momentum fluxes of the gravity waves during the measurement campaign, first the total kinetic and potential energy densities for the stratospheric height region were calculated (see Fig. 11). Potential (upper panel) as well as kinetic (lower panel) energy density show an overall similar temporal variation, whereas the kinetic component is about a factor of 2 higher than the potential one. Both time series in Fig. 11 reveal enhanced energy density during P3 and P7. The peak densities (P3 $\mathrm{E}_{\text {pot }}: 9 \pm 2.2 \mathrm{~J} / \mathrm{kg}$; $E_{\text {kin }}: 24 \pm 1.8 \mathrm{~J} / \mathrm{kg}$ and $P 7 \mathrm{E}_{\text {pot }}: 18 \pm 2.6 \mathrm{~J} / \mathrm{kg} ; \mathrm{E}_{\mathrm{kin}}: 33 \pm 0.8 \mathrm{~J} / \mathrm{kg}$ ) reach values around two times of the values during the other periods ( $\mathrm{E}_{\text {pot }}: 6.1 \pm 1.9 \mathrm{~J} / \mathrm{kg} ; \mathrm{E}_{\mathrm{kin}}: 13.9 \pm 1.7 \mathrm{~J} / \mathrm{kg}$ ). The enhanced values during P3 and P7 coincide with the meteorological events described in Section 3. This is a hint that both weather conditions may lead to enhanced amounts of energy being transported up- or downwards through the atmosphere.

Momentum fluxes are calculated to further quantify this finding. Fig. 12 presents the temporal variation of the vertical mean of zonal (red line, upper panel), meridional (blue line, upper panel) 

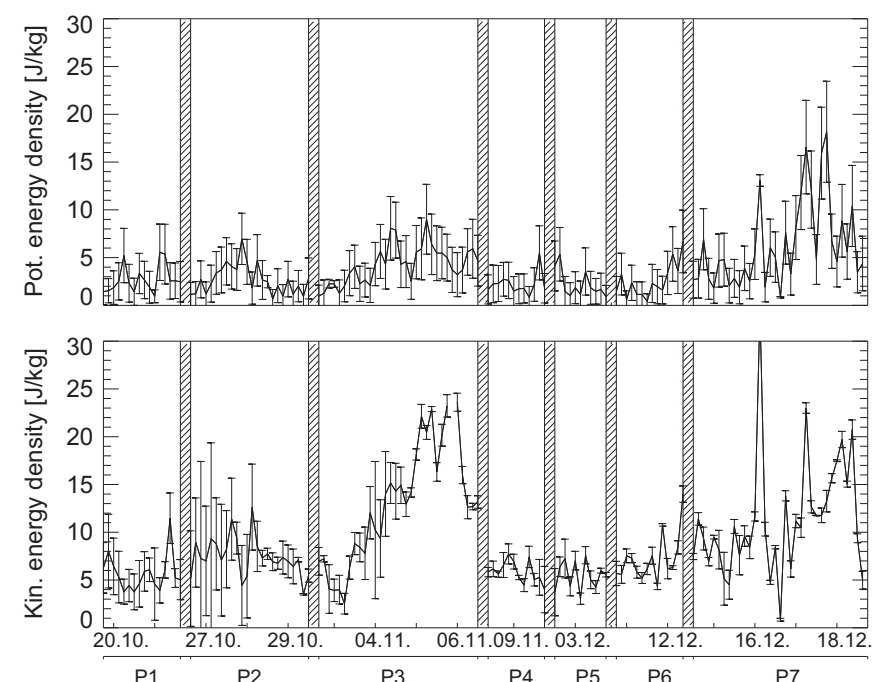

Fig. 11. Time series of energy densities per unit mass with error bars (potential energy: dashed line, kinetic energy: solid line) for the lower stratosphere.

and total (black line, lower panel) moment fluxes from 19th October 2011 until 18th December 2011 for the stratospheric height regime from 17 to $25 \mathrm{~km}$. Several peaks in the momentum flux are obvious. Especially, the beginning of November and mid of December are characterized by rather large amounts of momentum fluxes. These values correspond well to the weather situations described above (Medicane and frontal passages). While zonal and meridional fluxes are both positive during P3 (see black rectangle in Fig. 12), the frontal activity in period P7 leads to positive and negative values for the zonal and meridional component, respectively. Following the definition in Section 3 Eq. (11), these fluxes are all upwards, whereas their waves are propagating east- and northward during P3 but east- and southward during P7. Zhang et al. (2014) analyzed spatial and seasonal variability of GW momentum fluxes based on U.S. radiosonde data. They reported the zonal momentum flux maximum in the lower stratosphere in winter ranging between -0.02 and $0.14 \mathrm{~m}^{2} / \mathrm{s}^{2}$. These values are in agreement with our results during calm periods like P2 and at the end of P4.
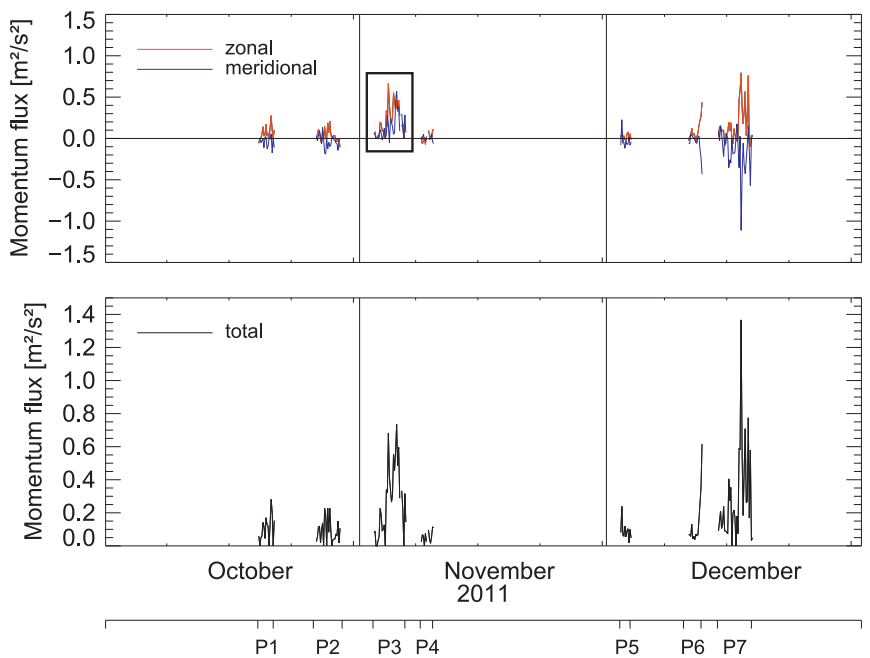

Fig. 12. Mean vertical flux of horizontal momentum for the altitude range between 17 and $25 \mathrm{~km}$; upper panel: zonal (red) and meridional (blue) momentum fluxes. Lower panel: total momentum fluxes are shown in black. The black rectangle in the upper panel marks the third time period of the campaign, where zonal and meridional fluxes are both positive. (For interpretation of the references to color in this figure legend, the reader is referred to the web version of this article.) a

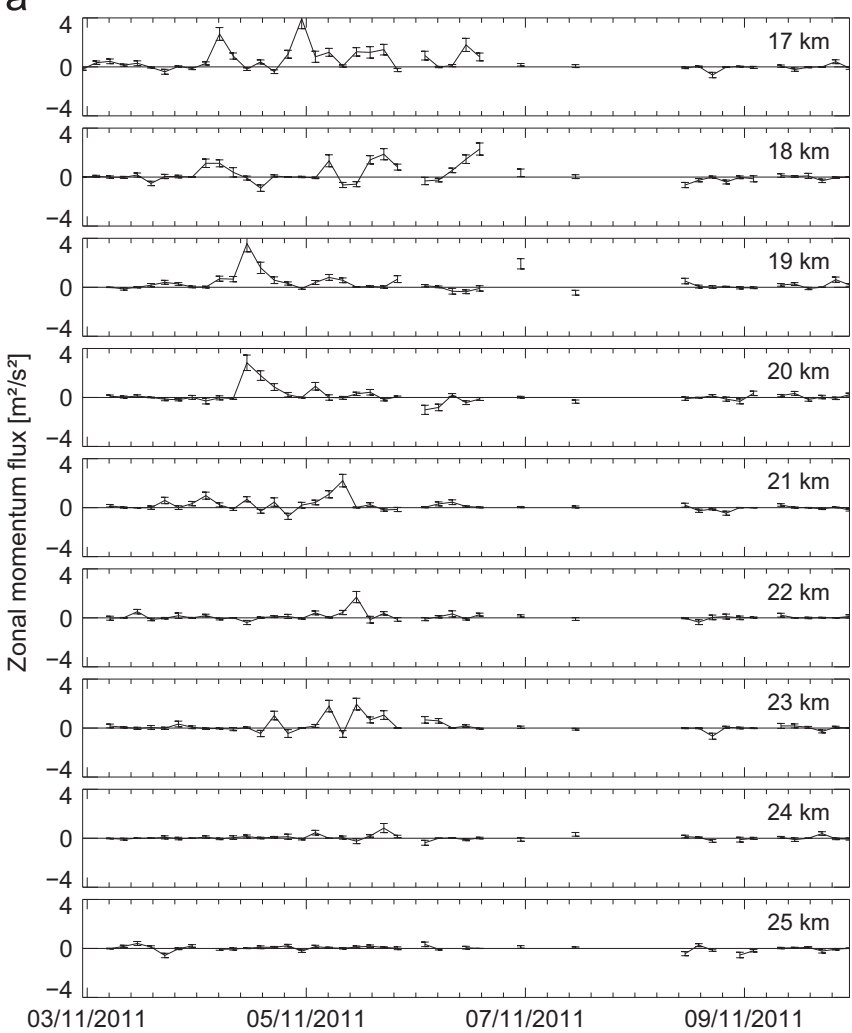

b

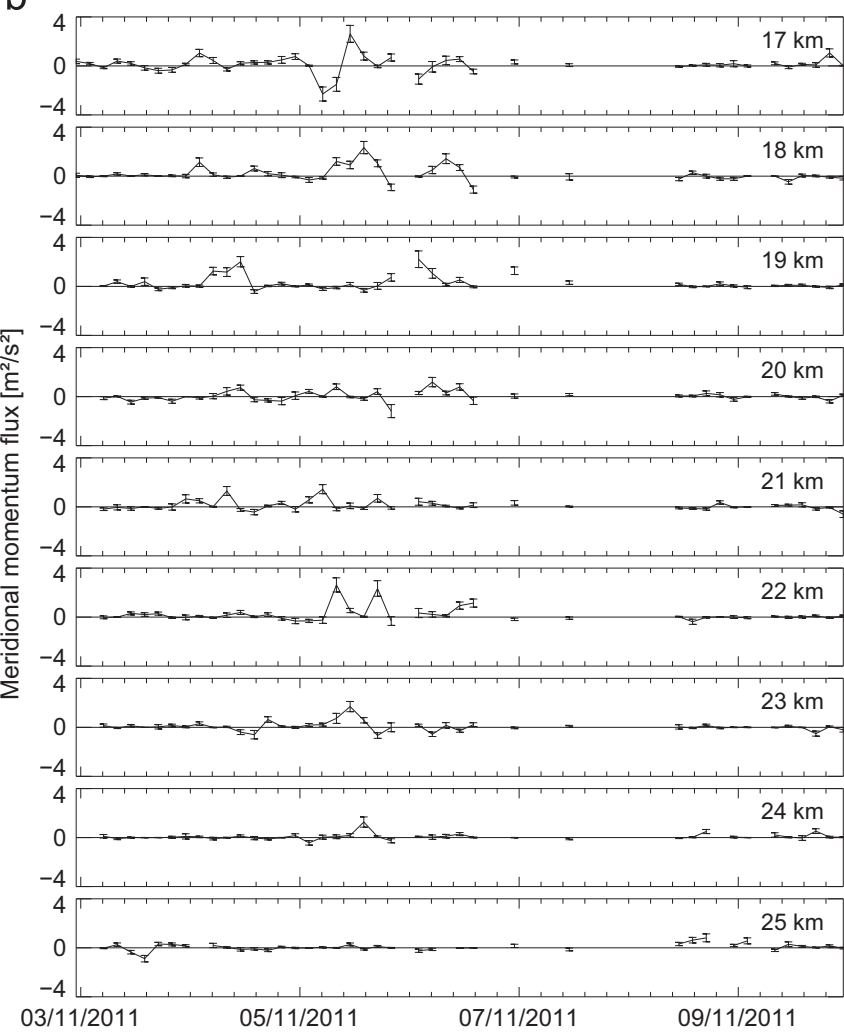

Fig. 13. Temporal evolution of the zonal (a) and meridional (b) momentum flux with error bars for the radiosonde measurements of 2nd November 2011, 23 UTC till 9th November 2011, 23 UTC.

Concerning the "Medicane"-period (P3-P4), the temporal evolution of zonal and meridional momentum flux is presented for the altitude ranges from 17 to $25 \mathrm{~km}$ in more detail (every $1 \mathrm{~km}$ ) 
a

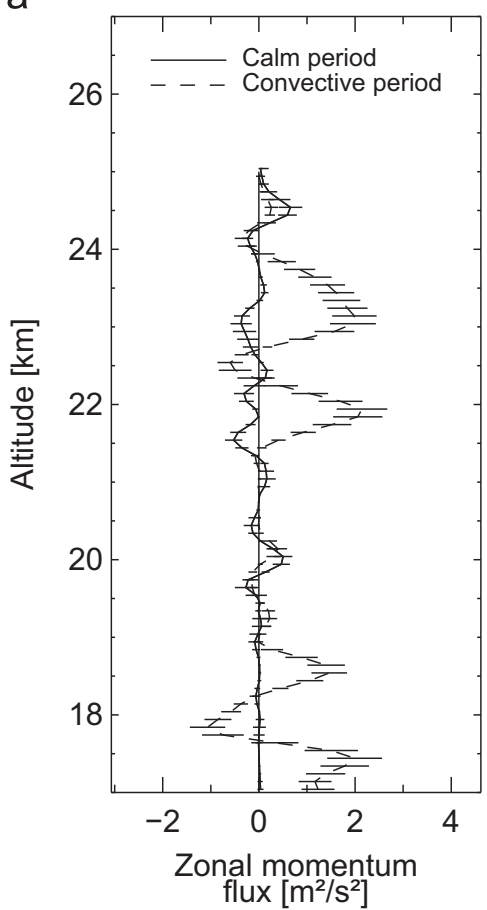

b

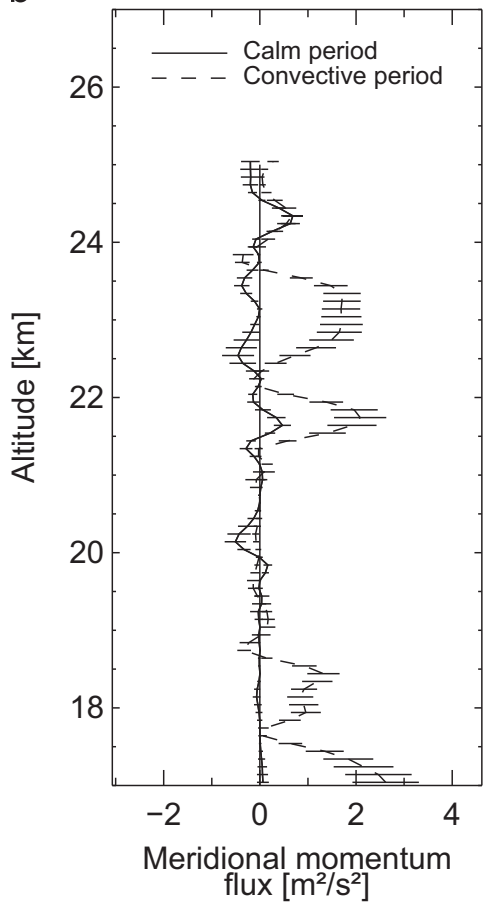

C

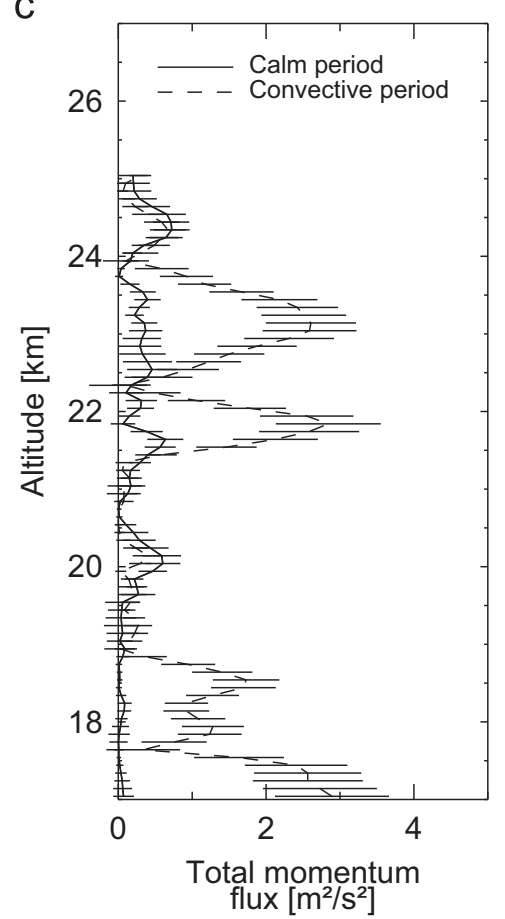

Fig. 14. Zonal (a), meridional (b) and total (c) momentum flux profiles with error bars during the convection period (dashed line) on 5.11 .2011 (routine radiosonde) and during a period without convection (solid line) on 31.10.2011 (RS-P3-23).

for 2nd November 2011, 23 UTC (RS-P3-3) until 9th November 2011, 23 UTC (RS-P4-13) (see Fig. 13). The zonal component (Fig. 13a) increases in the beginning of the strong convective period (4th November, 02 UTC; RS-P3-12). The intensification of momentum flux develops in most of the altitudes during the time interval of P3. At the end of this period (06.11.2011) the zonal momentum flux returns to lower values indicating that the center of the cyclone is drifting towards east and thus convection is reduced. In comparison to the zonal flux, the meridional component (Fig. 13b) appears more variable in time. While the zonal momentum flux is mainly positive, the meridional component changes from positive to negative values and vice versa. This means a change of upward northward flux to southward and backwards. Both parameters, zonal and meridional fluxes, show an enhancement during the convective period, up to ranges between $+4.0 \pm 0.15 \mathrm{~m}^{2} / \mathrm{s}^{2}$ and $-1.2 \pm 0.15 \mathrm{~m}^{2} / \mathrm{s}^{2}$ and $+4.9 \pm 0.15 \mathrm{~m}^{2} / \mathrm{s}^{2}$ and $-2.5 \pm 0.15 \mathrm{~m}^{2} / \mathrm{s}^{2}$, respectively.

It is instructive to compare the vertical momentum flux derived during a comparatively quiet weather period (see Fig. 14). For this purpose the routine radiosonde measurements of 31st October 2011, 23 UTC were used to represent a relative quiet period whereas the measurements taken on 5th November 2011, 11 UTC (RS-P3-23) represent a more disturbed situation. It is evident that the vertical fluxes between $\sim 20$ and $\sim 24 \mathrm{~km}$ altitude during the convective period are more than 10 times (almost 20 times) higher than the flux during a non-convective period. These results are for example in agreement with Nayar and Sreeletha (2003). They showed an enhancement of a factor of 10 of the vertical fluxes in $16 \mathrm{~km}$ altitude during a convective event. The results of Dutta et al. (2009) reveal a 5-10 times enhancement of the momentum fluxes observed on days after convective events in the stratosphere. As the peak values of momentum flux are not at the same height levels and therefore cannot directly be compared, the vertical fluxes are additionally integrated for the stratospheric altitude range and compared again. Thereby the mean flux for the quiet day derived for the height interval $17-25 \mathrm{~km}$ is $+1.1 \pm 0.1 \mathrm{~m}^{2} / \mathrm{s}^{2}$ for both components, whereas convective induced fluxes are more than 4 times higher with about $+5.0 \pm 0.2 \mathrm{~m}^{2} / \mathrm{s}^{2}$ for zonal as well as for meridional component. So, the convective days during the developing phase of the Mediterranean tropical storm yield an enhancement of vertical momentum fluxes of $+3.9 \pm 0.3 \mathrm{~m}^{2} / \mathrm{s}^{2}$ at maximum. Analyzing the convective day parameters shows that the significant minimum between 19 and $21 \mathrm{~km}$ altitude is due to minimum wind and temperature residuals. These are a result of the phasing of the superposed gravity waves.

\section{Summary and concluding remarks}

From 14th September 2011 to 10th January 2012 the CESAR ("Charakterisierung des differentiellen Energiegehaltes von VbZyklonen über die Quantifizierung abgestrahlter Schwere- und Infraschallwellen in der Atmosphäre", Wüst et al., 2013) measurement campaign took place at Palma de Mallorca $\left(39.6^{\circ} \mathrm{N}\right.$, $2.7^{\circ} \mathrm{E}$; Spain). A total of 143 radiosonde ascents were performed with high temporal resolution during seven distinct time periods. The ground-based infrared spectrometer GRIPS 12 has operated each night at Palma de Mallorca in order to obtain nocturnal temperatures at about $87 \mathrm{~km}$ height from airglow observations.

Several gravity wave parameters were derived from the radiosondes data (temperature and winds), such as vertical wavelengths, horizontal propagation directions, energy densities and momentum fluxes based on spectral analysis, hodograph and Stokes parameter analysis. Generally, the statistical features for GW parameters are consistent with previous radiosonde observations.

More interesting, we found strongly enhanced gravity wave activity in the lower stratosphere $(17-25 \mathrm{~km})$ during a hurricanelike storm (Medicane) and also during passing cold fronts. Based 
on our results, we assume that the sources of the enhanced gravity wave activity were due to convection processes related to the Medicane and to cold fronts. Evidence was found which suggested gravity wave upward propagation during the passing of cold fronts from lower stratospheric heights into the mesopause region, combining radiosonde, GRIPS airglow measurements and satellite data.

Comparison of quiet weather conditions (31st October 2011) with a strong convective situation during the Medicane period (5th November 2011) revealed that gravity wave momentum fluxes were strongly enhanced during convective conditions. An enhancement of a factor of almost 20 was found at selected altitudes.

According the prevailing wind directions, which are influenced usually through the so-called "Poniente" (a warm westerly wind coming directly from the Spanish mainland), and corresponding passages of convection, preferred horizontal propagation directions of the measured gravity waves are found to be oriented northwest and southeast.

In light of the predicted climate change induced change of storm/cyclone intensity (Graham and Diaz, 2001; Ulbrich et al., 2007), changes in cyclone induced GW activity can also be expected. Therefore, the observation and characterization of these gravity waves can help to improve GW parameterizations in both numerical climate and weather-forecasting applications. Finally, we have to point out that by using radiosonde data from more stations, we may observe the latitudinal and seasonal variation of cyclone induced gravity waves.

\section{Acknowledgments}

The authors thank the Bavarian State Ministry of the Environment and Public Health for funding the project CESAR (Az: U87292009/114-18-ZKL01Abt7_18459). We also thank the Spanish institution AEMET at Mallorca for greatly supporting the CESAR measurement campaign.

\section{References}

Alexander, M.J., May, P., Beres, J.H., 2004. Gravity waves generated by convection in the Darwin area during Darwin Area Wave Experiment. J. Geophys. Res. 109, D20S04. http://dx.doi.org/10.1029/2004JD004729.

Alexander, M.J., Geller, M., McLandress, C., Polavarapu, S., Preusse, P., Sassi, F., Sato, K. Eckermann, S., Ern, M., Hertzog, A., Kawatani, Y., Pulido, M., Shaw, T.A., Sigmond, M., Vincent, R., Watanabe, S., 2010. Recent developments in gravity-wave effects in climate models and global distribution of gravity-wave momentum flux from observations and models. Q. J. R. Meteorol. Soc. 136, 1103-1124.

Allen, S.J., Vincent, R.A., 1995. Gravity wave activity in the lower atmosphere: Seasonal and latitudinal variations. J. Geophys. Res. 100, 1327-1350.

Andrews, D.G., 2010. An introduction to atmospheric physics, Second Edition Cambridge University Press, New York, United States of America.

Axer, T., Bistry, T., Klawa, M., Müller, M., Süßer, M., 2012. Sturmdokumentation 2011. Deutsche Rück, Deutschland.

Bittner, M., Offermann, D., Bugaeva, I.V., Kokin, G.A., Koshelkov, J.P., Krivolutsky, A. Tarasenko, D.A., Gil-Ojeda, M., Hauchecorne, A., Lübken, F.-J., de la Morena, B.A., Mourier, A., Nakane, H., Oyama, K.I., Schmidlin, F.J., Soule, I., Thomas, L., Tsuda, T., 1994. Long period/large scale oscillations of temperature during the DYANA campaign. J. Atmos. Terr. Phys. 56, 1675-1700.

Bittner, M., Offermann, D., Graef, H.-H., Donner, M., Hamilton, K., 2002. An 18-year time series of $\mathrm{OH}$ rotational temperatures and middle atmosphere decadal variations. J. Atmos. Sol. Terr. Phys. 64, 1147-1166.

Dörnbrack, A., Birner, T., Fix, A., Flentje, H., Meister, A., Schmid, H., Browell, E. Mahoney, M., 2002. Evidence for inertia gravity waves forming polar stratospheric clouds over Scandinavia. J. Geophys. Res. 107, D20. http://dx.doi.org/ 10.1029/2001JD000452.

Doyle, J., Volkert, H., Dörnbrack, A., Hoinka, K., Hogan, T., 2002. Aircraft measurements and numerical simulations of mountain waves over the central Alps: A pre-MAP test case. Q. J. R. Meteorol. Soc. 128, 2175-2184

Dutta, G., Ayar Kumar, M.C., Vinay Kumar, P., Venkat Ratnam, M., Chandrashekar, M., Shibagaki, Y., Salauddin, M., Basha, H.A., 2009. Characteristics of high- frequency gravity waves generated by tropical deep convection: Case studies. J. Geophys. Res. 114, D18109. http://dx.doi.org/10.1029/2008JD011332.

Eckermann, S.D., 1996. Hodographic analysis of gravity waves: Relationships among Stokes parameters, rotary spectra and cross-spectral methods. J. Geophys. Res. 101, 19169-19174.

Eckermann, S.D., Vincent, R.A., 1989. Falling sphere observations of anisotropic gravity wave motions in the upper stratosphere over Australia. Pure Appl. Geophys. 130, 509-532.

Eckermann, S.D., Hirota, I., Hocking, W., 1994. Gravity wave and equatorial wave morphology of the stratosphere derived from long-term rocket soundings. Q. J. R. Meteorol. Soc. 121, 149-186.

Ern, M., Preusse, P., Alexander, M.J., Warner, C.D., 2004. Absolute values of gravity wave momentum flux derived from satellite data. J. Geophys. Res. 109, D20130. http://dx.doi.org/10.1029/2004JD004752.

Fritts, D.C., Vincent, R.A., 1987. Mesospheric momentum flux studies at Adelaide, Australia: Observations and a gravity wave-tidal interaction model. J. Atmos. Sci. 44, 605-619.

Fritts, D.C., Lu, W., 1993. Spectral estimates of gravity wave and energy fluxes. Part II: Parameterization of wave forcing and variability. J. Atmos. Sci. 50 (22), 3695-3713.

Fritts, D.C., vanZandt, T., 1993. Spectral estimates of gravity wave and energy fluxes. Part I: Energy, dissipation, acceleration and constraints. J. Atmos. Sci. 50 (22), 3685-3694.

Fritts, D.C., Alexander, M.J., 2003. Gravity wave dynamics and effects in the middle atmosphere. Rev. Geophys. 41 (1), 1003. http://dx.doi.org/10.1029/ 2001RG000106.

Fritts, D.C., Vadas, S.L., Wan, K., Werne, J.A., 2006. Mean and variable forcing of the middle atmosphere by gravity waves. J. Atmos. Sol. Terr. Phys. 68, 247-265. http://dx.doi.org/10.1016/j.jastp.2005.04.010

Gong, J., Geller, M.A., Wang, L., 2008. Source spectra information derived from U.S. high-resolution radiosonde data. J. Geophys. Res. 113, D10106. http://dx.doi.org/ 10.1029/2007JD009252.

Graham, N.E., Diaz, H.F., 2001. Evidence for intensification of North Pacific winter cyclones since 1948. Bull. Am. Meteorol. Soc. 82 (9), 1869-1893.

Hamilton, K., 1991. Climatological statistics of stratospheric inertia-gravity waves deduced from historical rocketsonde wind and temperature data. J. Geophys. Res. 96, 20829-20831.

Hines, C.O., 1960. Internal atmospheric gravity waves at ionospheric heights. Can. J. Phys. 38, 1441-1481.

Hines, C.O., 1991. The saturation of gravity waves in the middle atmosphere, II, Development of Doppler-spread theory. J. Atmos. Sci. 48, 1360-1379.

Hines, C.O., Tarasick, D.W., 1987. On the detection and utilization of waves in airglow studies. Planet. Space Sci. 35 (7), 851-866.

Hirota, I., Niki, T., 1985. A statistical study of inertia-gravity waves in the middle atmosphere. J. Meteorol. Soc. Jpn. 63, 1055-1066.

Holton, J.R., 1983. The influence of gravity wave breaking on the general circulation of the middle atmosphere. J. Atmos. Sci. 46, 2497-2507.

Kim, Y.J., Arakawa, A., 1995. Improvement of orographic gravity wave parameterization using a mesoscale gravity wave model. J. Atmos. Sci. 52 $1875-1902$.

Kyle, T.H., 1993. Atmospheric Transmissions, Emission and Scattering. Pergamon Press, Oxford, England.

Lehmann, C.I., Kim, Y.-H., Preusse, P., Chun, H.-Y., Ern, M., Kim, S.-Y., 2012. Consistency between Fourier transform and small-volume few-wave decomposition for spectral and spatial variability of gravity waves above a typhoon. Atmos. Meas. Tech 5, 1637-1651.

Li, T., Leblanc, T., McDermid, I., Wu, D., Dou, X., Wang, S., 2010. Seasonal and interannual variability of gravity wave activity revealed by long-term lidar observations over Mauna Loa Observatory, Hawaii. J. Geophys. Res. 115, D13103. http://dx.doi.org/10.1029/2009JD013586.

Lindzen, R.S., Holton, J.R., 1968. A theory of the quasi-biennial oscillation. J. Atmos. Sci. 25, 1095-1107.

McFarlane, N.A., 1987. The effect of orographically excited gravity wave drag on the general circulation of the lower stratosphere and troposphere. J. Atmos. Sci. 44 (14), 1775-1800

Miglietta, M.M., Laviola, S., Malvaldi, A., Conte, D., Levizzani, V., Price, C., 2013. Analysis of tropical-like cyclones over the Mediterranean Sea through a combined modeling and satellite approach. Geophys. Res. Lett. 40, 1-6. http://dx. doi.org/10.1002/grl.50432

Mitchell, N.J., Thomas, L., Prichard, I.T., 1994. Gravity waves in the stratosphere and troposphere observed by lidar and MST radar. J. Atmos. Terr. Phys. 56, 939-947.

Nastrom, G.D., Fritts, D.C., Gage, K.S., 1987. An investigation of terrain effects on the mesoscale spectrum of atmospheric motions. J. Atmos. Sci. 44, 3087-3096.

Nayar, S.R.P., Sreeletha, S., 2003. Momentum flux associated with gravity waves in the low-latitude troposphere. Ann. Geophys. 21, 1183-1195.

Pfenninger, M., Ziu, A., Papen, G., Gardner, C., 1999. Gravity wave characteristics in the lower atmosphere at South Pole. J. Geophys. Res. 104 (D6), 5963-5984.

Piani, C., Durran, D.R., Alexander, M.J., Holton, J.R., 1999. A numerical study of threedimensional gravity waves triggered by deep convection and their role in the dynamics of the QBO. J. Atmos. Sci. 57 (22), 3689-3702.

Preusse, P., Dörnbrack, A., Eckermann, S.D., Riese, M., Schaeler, B., Bachmeister, J.T., Broutman, D., Grossmann, K.U., 2002. Space-based measurements of stratospheric mountain waves by CRISTA. 1. Sensitivity, analysis method, and a case study. J. Geophys. Res. 107, 8178. http://dx.doi.org/10.1029/2001JD000699.

Pulido, M., Polavarapu, S., Shepherd, T.G., Thuburn, J., 2012. Estimation of optima gravity wave parameters for climate models using data assimilation. Q. J. R. Meteorol. Soc. 138, 298-309. 
Sato, K., 1994. A statistical study of the structure, saturation and sources of inertiagravity waves in the lower stratosphere observed with the MU radar. J. Atmos. Terr. Phys. 56, 755-774.

Sato, K., O'Sullivan, D., Dunkerton, T.J., 1997. Low-frequency inertia-gravity waves in the stratosphere revealed by three-week continuous observation with the MU radar. Geophys. Res. Lett. 24, 1739-1742.

Sato, K., Tateno, S., Watanabe, S., Kawatani, Y., 2011. Gravity wave characteristics in the southern hemisphere revealed by a high-resolution middle-atmosphere general circulation model. J. Atmos. Sci. 69, 1378-1396. http://dx.doi.org/ 10.1175/JAS-D-11-0101.1.

Schmidt, C., Höppner, K., Bittner, M., 2013. A ground-based spectrometer equipped with an InGaAs array for routine observations of $\mathrm{OH}(3-1)$ rotational temperatures in the mesopause region located at the NDMC-station Oberpfaffenhofen, Germany. J. Atmos. Sol. Terr. Phys. 102, 125-139. http://dx.doi.org/10.1016/j. jastp.2013.05.001.

Stevens, B., Giorgetta, M., Esch, M., Mauritsen, T., Crueger, T., Rast, S., Salzmann, M., Schmidt, H., Bader, J., Block, K., Brokopf, R., Fast, I., Kinne, S., Kornblueh, L., Lohmann, U., Pincus, R., Reichler, T., Roeckner, E., 2013. Atmospheric component of the MPI-M Earth System Model: ECHAM6. J. Adv. Model. Earth Syst. 5, 1-27. http://dx.doi.org/10.1002/jame.20015.

Suzuki, S., Lübken, F.-J., Baumgarten, G., Kaifler, N., Eixmann, R., Williams, B.P., Nakamura, T., 2013. Vertical propagation of a mesoscale gravity wave from the lower to the upper atmosphere. J. Atmos. Sol. Terr. Phys. 97, 29-36. http://dx. doi.org/10.1016/j.jastp.2013.01.012.

Swenson, G.R., Alexander, M.J., Haque, R., 2000. Dispersion imposed limits on atmospheric gravity waves in the mesosphere: observations from $\mathrm{OH}$ airglow. Geophys. Res. Lett. 27 (6), 875-878.

Thrane. E.V., Turbulenz in der mittleren Atmosphäre, Promet. 22, 1992, pp. 2-4.

Tsuda, T., Kato, S., Yokoi, T., Inoue, T., Yamamoto, M., VanZandt, T.E., Fukao, S., Sato, T., 1990. Gravity waves in the mesosphere observed with the MU radar. Radio Sci. 26, 1005-1018

Tsuda, T., VanZandt, T.E., Mizumoto, M., Kato, S., Fukao, S., 1991. Spectral analysis of temperature and Brunt-Väisalä frequency fluctuations observed by radiosondes. J. Geophys. Res. 96, 17265-17287.

Ulbrich, U., Pinto, J.G., Kupfer, H., Leckebusch, G.C., Spangehl, T., Reyers, M., 2007. Changing northern hemisphere storm tracks in an Ensemble of IPCC climate change simulations. J. Clim. 21, 1669-1679.
Vincent, R.A., Fritts, D.C., 1987. A climatology of gravity wave motions in the mesopause region at Adelaide, Australia. J. Atmos. Sci. 44 (4), 748-760.

Vincent, R.A., Allen, S.J., Eckermann, S.D., 1997. Gravity-Wave Parameters in the Lower Stratosphere, Gravity Wave Processes: Their Parameterization In Globa Climate Models In: Hamilton, K. (Ed.), NATO ASI Ser. I, 50. Springer-Verlag, pp. 7-25.

Vincent, R.A., Alexander, M.J., 2000. Gravity waves in the lower stratosphere: An observational study of seasonal and interannual variability. J. Geophys. Res. 105 17971-17982.

Wang, L., Geller, M.A., 2003. Morphology of gravity-wave energy as observed from 4 years (1998-2001) of high vertical resolution U.S. radiosonde data. J. Geophys. Res. 108 (D16), 4489. http://dx.doi.org/10.1029/2002JD002786.

Wang, L., Geller, M.A., Alexander, M.J., 2005. Spatial and temporal variations of gravity wave parameters. Part I: Intrinsic frequency, wavelength, and vertical propagation direction. J. Atmos. Sci. 62, 125-142. http://dx.doi.org/10.1175/JAS3364.1 .

Wang, L., Fritts, D.C., Williams, B.P., Goldberg, R.A., Schmidlin, F.J., Blum, U., 2006. Gravity waves in the middle atmosphere during the MaCWAVE winter campaign: evidence of mountain wave critical level encounters. Ann. Geophys. 24 1209-1226.

Wüst, S., Bittner, M., 2006. Non-linear resonant wave-wave interaction (triad): Case studies based on rocket data and first application to satellite data. J. Atmos. Sol. Terr. Phys. 68, 959-976. http://dx.doi.org/10.1016/j.jastp.2005.11.011.

Wüst, S., Bittner, M., 2008. Gravity wave reflection: Case study based on rocket data. J. Atmos. Sol. Terr. Phys. 70, 742-755.

Wüst, S., Kramer, R., Pilger, C., Bittner, M., 2013. Ein neuer Ansatz zur Abschätzung des Schadenspotentials von Vb-Wetterlagen: CESAR, Schlussbericht.

Yoshiki, M., Sato, K., 2000. A statistical study of gravity waves in the Polar Regions based on operational radiosonde data. J. Geophys. Res. 105, 17995-18011.

Zhang, S., Yi, F., Huang, C., Huang, K., 2012. High vertical resolution analyses of gravity waves and turbulence at a midlatitude station. J. Geophys. Res. 117, D02103. http://dx.doi.org/10.1029/2011JD016587.

Zhang, S.D., Huang, C.M., Huang, K.M., Yi, F., Zhang, Y.H., Gan, Q. Gong, Y., 2014 Spatial and seasonal variability of medium- and high- frequency gravity waves in the lower atmosphere revealed by U.S. radiosonde data. Ann. Geophys. 32, 1129-1143. http://dx.doi.org/10.5194/angeo-32-1129-2014. 